\section{Diversity and convergences in the evolution of feeding adaptations in ankylosaurs}

\section{(Dinosauria: Ornithischia)}

Attila Ösi ${ }^{1,2 *}$, Edina Prondvai ${ }^{2,3}$, Jordan Mallon $^{4}$, Emese Réka Bodor $^{5}$

${ }^{1}$ Department of Paleontology, Eötvös University, Budapest, Pázmány Péter sétány 1/c, 1117, Hungary; +36 3037487 63; hungaros@gmail.com

${ }^{2}$ MTA-ELTE Lendület Dinosaur Research Group, Budapest, Pázmány Péter sétány 1/c, 1117, Hungary; +36 7094551 91; hungaros@gmail.com

${ }^{3}$ University of Gent, Evolutionary Morphology of Vertebrates Research Group, K.L.

Ledegankstraat 35, Gent, Belgium; +32 471 990733; edina.prondvai@gmail.com

${ }^{4}$ Palaeobiology, Canadian Museum of Nature, PO Box 3443, Station D, Ottawa, Ontario, K1P

6P4, Canada; +1 613364 4094; jmallon@mus-nature.ca

${ }^{5}$ Geological and Geophysical Institute of Hungary, Budapest, Stefánia út 14, 1143, Hungary; +36 70948 0248; emesebodor@gmail.com

Research was conducted at the Eötvös Loránd University, Budapest, Hungary.

*Corresponding author: Attila Ösi, hungaros@gmail.com

\section{Acknowledgements}

This work was supported by the MTA-ELTE Lendület Programme (Grant No. LP 95102), OTKA (Grant No. T 38045, PD 73021, NF 84193, K 116665), National Geographic Society (Grant No. 7228-02, 7508-03), Bakonyi Bauxitbánya Ltd, Geovolán Ltd, Hungarian Natural History Museum, Hungarian Academy of Sciences, Canadian Museum of Nature, The Jurassic Foundation, Hantken Miksa Foundation, Eötvös Loránd University.

Disclosure statment: All authors declare that there is no financial interest or benefit arising from the direct application of this research.
Törölt: Diversity of feeding characters explains evolutionary success of ankylosaurs (Dinosauria: Ornithischia)

Formázott: Betütípus: Félkövér

Formázott: Betűtípus: Félkövér

Formázott: Betútípus: Félkövér

Formázott: Betűtípus: Félkövér 


\begin{abstract}
Ankylosaurian dinosaurs were low-browsing quadrupeds that were thought of as simple orthal pulpers exhibiting minimal tooth occlusion during feeding, as in many extant lizards. Recent studies, however, have demonstrated that effective chewing with tooth-tooth occlusion and palinal jaw movement was present in some members of this group. Qualitative and quantitative analysis of feeding characters (i.e. craniodental features, tooth wear patterns, origin and insertion of jaw adductors) reveal at least three different jaw mechanisms during the evolution of Ankylosauria. Whereas, in basal members, food processing was restricted to simple orthal pulping, in late Early and Late Cretaceous North American and European forms a precise tooth occlusion evolved convergently in many lineages (including nodosaurids and ankylosaurids) complemented by palinal power stroke. In contrast, Asian forms retained the primitive mode of feeding without any complex chewing, a phenomenon that might relate to the different types of vegetation consumed by these low-level feeders in different habitats on different landmasses. On the other hand, a progressive widening of the muzzle is demonstrated both in Late Cretaceous North American and Asian ankylosaurs, and the width and general shape of the muzzle probably correlates with foraging time and food type, as in herbivorous mammals.
\end{abstract}

Key words: Ankylosauria, feeding characters, tooth wear, dental occlusion, palinal jaw movement, herbivory 


\section{Introduction}

Ankylosaurs were dominantly herbivorous dinosaurs during the last 100 million years of the

Törölt: important Mesozoic. They are known from the Middle Jurassic to the end of the Cretaceous (CallovianMaastrichtian) on all continents except Africa. As massively built quadrupeds with short forelimbs and low-slung heads, ankylosaurs were typical low-level browsers (Vickaryous et al. 2004, Mallon and Anderson 2013) capable of reaching no higher than $\sim 1.5 \mathrm{~m}$ above the ground (Bakker 1978; Weishampel and Norman 1989; Carpenter 2004; Mallon et al. 2013). Cololite in the Australian Kunbarrasaurus (Leahey et al. 2015), consisting of plant remains including fragments of vascular tissue, seed-bearing organs, seed and possible sporangia, suggest the feeding of soft vegetation at least in some forms (Molnar and Clifford 2000; Molnar and Clifford 2001). On the other hand, fish remains in gut or stomach contents of the $\underline{\text { small bodied Liaoningosaurus suggest that some species might have been at least partly }}$ piscivorous (Ji et al. 2014). The relatively small, thinly enamelled and leaf-shaped teeth bear wear facets, oversight of which led earlier workers to suggest that oral processing in these animals was restricted to simple orthal pulping, as in many extant lizards (Owen 1861; Weishampel 1984; Galton 1986; Weishampel and Norman 1989; King 1996; Hwang 2005). However, several recently recognized craniodental features (e.g., fleshy cheeks, complex hyobranchial apparatus, precise tooth occlusion, biphasal jaw mechanism; Galton 1973; Maryanska 1977; Barrett 2001; Rybzynski and Vickaryous 2001; Carpenter 2004; Mallon and Anderson 2014a; Mallon and Anderson 2014b; Ösi et al. 2014a; Hill et al. 2015) indicate that, similar to ornithopods and marginocephalians, feeding movements in ankylosaur jaws were probably more complex than initially thought.

The present study is a first attempt to examine the aforementioned ankylosaur feeding characters in an evolutionary context (Figure 1, Table 1). In addition to comparative description of these features, we apply traditional morphometric methods to the skulls and 
mandibles of the most relevant taxa to infer the evolution of key feeding specializations.

Analyses of dental macrowear and microwear patterns further document changes in the feeding mode and dietary preference. Together, these observations give important insight into the ecomorphological factors that led to the evolutionary success of the group.

\section{Material and methods}

\subsection{Materials}

Sixty-five ankylosaur species were examined (Table 1), representing most of the valid species known to date (Vickaryous et al. 2004; Arbour and Currie 2016). Twenty-seven species were studied first-hand, and the remainder were examined on the basis of the available literature or photographs. Cranial material was available for 52 species, 36 of which have in situ or associated teeth. Twenty-four species were used for cranial morphometric analysis (Supplementary data 1), and 15 have teeth adequate for wear analysis (Table 2). Specimens of some species not included in the wear analysis (e.g., Pinacosaurus mephistocephalus [Godefroit et al. 1999], Liaoningosaurus [Xu et al. 2001], Zhongyuansaurus [Xu et al. 2007]) also possess in situ dentition; however, we had no access to them. In Chuanqilong, the maxillary teeth are poorly preserved and exposed only in labial view (Han et al. 2014:fig. 4C), preventing examination of the more informative lingual (working) side of the crowns. Specimens of other taxa (e.g. Stegopelta [Moodie 1910], Priconodon [USNM 2135, Lull et al. 1911], Texastes [Coombs 1995], Antarctopelta [Gasparini et al. 1996], Pawpawsaurus [Lee 1996], Kunbarrasaurus [Leahey et al. 2015], Niobrarasaurus [Carpenter et al. 1995], Dyoplosaurus [Arbour et al. 2009], Tatankacephalus [Parsons and Parsons 2009]) also possess teeth, sometimes with wear facets, but the low tooth count and/or poor preservation do not allow us to infer details of tooth occlusion or jaw mechanics. Additionally, specimens of many taxa possess exclusively or mostly unerupted replacement teeth (e.g. Sarcolestes 
[Galton 1983], Priodontognathus [Galton 1980a], Crichtonpelta [Dong 2002], Animantarx

[Carpenter et al. 1999], Peloroplites [Carpenter et al. 2008]) which are useless for tooth wear analysis.

In four genera of nodosaurids (Gargoyleosaurus, Hungarosaurus, Panoplosaurus CMN 2759 and 3 specimens of Edmontonia spp.: CMN 8531, ROM 1215, TMP 98.98.01) and four species of ankylosaurids (Maleevus disparoserratus, Saichania chulsanensis, Euoplocephalus tutus, Ankylosaurus magniventris) in situ teeth are available and suitable for microwear analysis.

Some taxa (e.g. Sauropelta edwardsi, Edmontonia spp., Euoplocephalus tutus, Ankylosaurus magniventris) known from multiple specimens were used in both the morphometric and tooth wear analyses to better understand patterns of intraspecific variation. Given uncertainty regarding the assignment of various specimens to Panoplosaurus mirus, Edmontonia longiceps and E. rugosidens (Burns and Currie 2012), we refer only the type specimen CMN 2759 to Panoplosaurus mirus. The other specimens, variably assigned to any of these three species, are referred to as Edmontonia.

For institutional abbreviations to the specimens used in the text, tables and supplementary files, see Supplementary data 2.

\subsection{Methods}

In our consideration of ankylosaur feeding, we examined both qualitative and quantitative variables relating to the skull. The former include the quadrate-articular joint, the intermandibular joint (symphysis), muzzle shape, tooth shape, and jaw adductor muscle attachment sites. These are described either from first-hand observations or from photographs. Our analysis of quantitative variables is described below. 


\subsubsection{Cranial morphometrics}

Our morphometric analysis was based on that of Mallon and Anderson (2013). These authors took 10 linear measurements from the cranium and two from the mandible to produce an ecomorphological model for the megaherbivorous dinosaurs of the Upper Cretaceous Dinosaur Park Formation. We eliminated one of the cranial measurements ('depression of snout below occlusal plane': variable 10 of Mallon and Anderson 2013) because this feature is difficult to measure in most ankylosaurs due to the frequent dorsoventral compression of the lightly built muzzle. Following Bowman (1961), we added some new linear measurements that may also reflect functional differences in feeding adaptations (for the list of craniomandibular measurements see Supplementary data 1, for graphical representation of the measurements see Figure 2).

\subsubsection{Quantitative analyses}

All quantitative analyses were performed in PAST version 2.17c (Hammer et al. 2001).

Correlation among the measured variables was tested using a Pearson correlation analysis. Principal component analysis (PCA) was performed on the variance-covariance matrix of standardized and row-normalized data to ensure equal character weights and to focus on shape variance by minimizing the effect of absolute size on the results. We recognize that size is an important ecological discriminator between species (Peters 1983), but given our focus on shape differences and their influence on feeding mechanics, it was ignored. Cranial and mandibular measurements were analysed separately to maximise the number of specimens available for each functional complex.

\subsubsection{Tooth wear analysis}


Ankylosaur teeth have labiolingually compressed, mesiodistally denticulate crowns with a mesiodistal width usually ranging from 3 to $12 \mathrm{~mm}$. Most species possess a basal cingulum both on the labial and lingual sides that can be smooth or more frequently crenulated. In some forms, especially in nodosaurids, the cingulum is better developed on the labial side of both the maxillary and dentary teeth (Coombs 1990; Mallon and Anderson 2014a). This crown morphology restricts macrowear and microwear features to the labiolingual surfaces and the cuspidate carinae of the teeth. As in most toothed tetrapods, the upper teeth of ankylosaurs are positioned labially relative to the lower teeth so that attritional wear mainly occurs on the lingual side of the upper and the labial side of the lower teeth. In some cases (e.g. TMP 92.36.313, referred to as Panoplosaurus), a reverse wear pattern may occur; however, this appears to be related to malocclusion. We follow Smith and Dodson (2003) in numbering tooth positions sequentially from anterior to posterior.

In describing macrowear features, we note the positions of wear facets on the crown, orientation relative to the crown axes, and their size relative to crown area. The nature of the enamel-dentine interface (EDI) is also used as a means to determine jaw mechanics.

Following earlier authors (e.g. Greaves 1973, Rensberger 1973, Weishampel 1984), a flush interface occurs at the leading edge of the wear facet (where the hard enamel protects the underlying dentine), and a stepped interface occurs at the trailing edge (Figure 3).

Microwear features are typically produced during feeding, and are manifested as scratches and pits. Following Ungar (1996), pits are defined as having a length : width ratio smaller than $4: 1$. In scratches, this ratio is greater than $4: 1$.

Macrowear patterns were initially examined using light microscopy. Detailed examination of the EDI and microwear features was conducted using a Hitachi S-2360N scanning electron microscope (SEM). High resolution molds were taken from all teeth used in this study, following the procedure described by Grine (1986). Specimens were first cleaned with cotton 
swabs soaked with ethanol. Impressions were then made using Coltene President Jet Regular (polysiloxane vinyl) impression material, and casts were made with EPO-TEK 301 epoxy resin. This procedure reproduces features with a resolution of a fraction of a micron. Casts were then sputter-coated with approximately $5 \mathrm{~nm}$ of gold, and examined using the SEM at 20 $\mathrm{kV}$. Images of the microwear sites were taken at magnifications of up to $150 \mathrm{x}$ for most specimens. Forty micrographs of both enamel and dentine surfaces were analysed. Each micrograph was saved at 200 dpi resolution, then cropped to a $640 \times 480$ pixel image ( $850 \mu \mathrm{m}$ $\times 570 \mu \mathrm{m})$ and saved as a grayscale image file. These microwear images were analyzed using MICROWARE 4.0 following the procedure described by Ungar (1995). Five variables were quantified on the micrographs: 1) pit percentage, 2) mean scratch width, 3) mean scratch length, 4) mean pit width, and 5) mean pit length. We also report the total number of measured features and the standard deviation of means for comparison among the different taxa (Table 3).

\subsubsection{Jaw adductor reconstruction}

Based on the extant phylogenetic bracket (Witmer 1995), it is supposed that jaw adductor musculature in ankylosaurs was similar to that of extant archosaurs (e.g. Iordansky 1964 , Busbey 1989, Baumel 1993; Holliday and Witmer 2007; Holliday 2009), so the position of the origin and insertion surfaces of jaw adductors are suggested to be on the same elements as those of extant archosaurs. In ankylosaurs, jaw adductors have already been reconstructed for Panoplosaurus (Holliday 2009), Hungarosaurus (Ösi et al. 2014a), Euoplocephalus (Haas 1969; Coombs 1971) and Saichania (Carpenter et al. 2011). In this work, we mainly followed the interpretations of Holliday (2009) completed with personal observations examining the bony features (muscle scars) on the available specimens. 


\section{Results}

\subsection{Morphometric analysis of the skull and mandible}

Among cranial measurements, correlation is highest between paroccipital process breadth $(\mathrm{PPB})$ and distance between quadrate condyles $(\mathrm{DQ})\left(\mathrm{r}^{2}=0.95\right)$, and between anterior and posterior muzzle width (AMW and MW, respectively) $\left(\mathrm{r}^{2}=0.89\right)$. Correlation among mandibular variables is generally lower, with the strongest correlation $\left(r^{2}=0.85\right)$ between mandible length and depth (ML and MD, respectively). Only nine of the 55 cranial correlation values, and four of the six mandibular correlation values, are above 0.5 , meaning that PCA is suitable for describing the data structure. Pairwise correlations among different characters are shown in Supplementary data 3

Due to the elimination of size effects via data transformation (see methods above), shape variance is evenly distributed across PC axes. In the case of the cranial variables, PC1 explains approximately $30 \%$ of the variance, and PC2 accounts for $21.5 \%$. Posterior and anterior muzzle width (MW and AMW, respectively) load most heavily and positively PC1, while maxillary tooth row length (TRL) has a lower but still considerable and negative loading on this axis (Figure 4(A)). This pattern suggests a relative widening and shortening of the snout moving in the positive direction along PC 1 . The major positive and negative contributors to PC2 are temporal fossa length (TFL) and paroccipital process breadth (PPB), respectively, suggesting that positive values on PC2 represent skulls with elongate temporal fossae (presumably equating to larger jaw adductors) and a narrow posterior region. Thus, specimens with short, wide snouts and relatively posteriorly narrow skulls, (e.g., the nodosaurid Edmontonia USNM 11868) are positioned in the upper right quadrant (positive PC1 and PC2 values), whereas those with elongate, narrow snouts and posteriorly wide crania (e.g., the ankylosaurid Gobisaurus IVPP V12563), are located in the lower left quadrant (negative PC1 and PC2 values) (Figure 4(A)). 
In the mandible morphospace, PC1 explains $62 \%$ of the variance, whereas PC2 accounts for $30 \%$. Mandible length (ML) loads strongly negatively on PC1, while glenoid-coronoid process distance (JCP) and glenoid-occlusal plane distance (DGO) have less substantial but positive loadings on PC1. Thus, increasingly positive scores on PC1 represent relative shortening of the mandibles with a concomitant enlargement of the coronoid process and lowering of the glenoid relative to the occlusal plane. PC2, conseversely, is dominated by the effect of mandible depth (MD) which loads positively on this axis. Thus, specimens exhibiting relatively short and narrow jaws with an enlarged area for adductor muscle insertion and a ventrally displaced glenoid (e.g. the nodosaurids Hungarosaurus and Panoplosaurus) occur in the lower right quadrant (negative PC1 and PC2 scores), while specimens exhibiting deeper and more elongate jaws with less extensive adductor insertion sites (e.g., the ankylosaurids Euoplocephalus and Ankylosaurus) occur in the upper left quadrant (positive PC1 and PC 2 scores) (Figure 4(B)).

\subsection{Muzzle shape}

As demonstrated by PCA, muzzle width varies considerably within Ankylosauria (Figure 4(A), 5). The ventral outline of the muzzle is likewise quite variable (Figure 5; Mallon and Anderson, 2014:fig. 5). Whereas, in some forms, the muzzle is rectangular/trapezoidal in ventral view (e.g. Pawpawsaurus, Panoplosaurus [CMN 2759, Figure 5(G)], Edmontonia [USNM 11868, Figure 5(F)]), in other forms (e.g. Euoplocephalus [AMNH 5405, Figure 5(L)], Edmontonia [ROM 1215, Figure 5(E)], Hungarosaurus [Figure 5(D)]) it is rounded or pointed (Cedarpelta, Gobisaurus, Shamosaurus). A progressive widening of the premaxillae can only be unambiguously demonstrated in the lineage of Asian ankylosaurids (Figure 6). Mid-Cretaceous Asian forms (Gobisaurus [Figure 5J], Shamosaurus [Figure 5(I)], Crichtonpelta) retain a narrow, pointed muzzle, whereas Turonian-Maastrichtian forms 
(Tsagantegia, Saichania [Figure 5(K)], Tarchia) possess a wide, sometimes rectangular muzzle.

\section{In Cedarpelta, as an Early Cretaceous representative of North American ankylosaurids}

(Arbour et al. 2016), the muzzle is still narrow. The phylogenetic analysis of Arbour and Currie (2016) suggests that Late Cretaceous ankylosaurids in North America (i.e.

Ankylosaurini) are the descendants of Asian ancestors that immigrated to North America no later than the Campanian. Similar to their Turonian-Maastrichtian-aged Asian relatives, these North American ankylosaurids (e.g. Euoplocephalus, Ankylosaurus, Scolosaurus, Anodontosaurus) also possessed anteroposteriorly short and wide, edentulous muzzles (Figure $6)$.

Among North American nodosaurids, a progressive widening of the muzzle is observed (Figure 6), but there is also great variability in muzzle outline (Figure 5). The earliest ankylosaur with preserved premaxillae is the basal nodosaurid Gargoyleosaurus, which possesses a narrow, toothed, and trapezoidal muzzle (Figure 5(A)). The Barremian Gastonia, variably classified as either a nodosaurid (Thompson et al. 2012; Arbour et al. 2016) or a basal ankylosaurid (Arbour and Currie 2016), has an edentulous muzzle that is much wider (Figure 5(H)) than that of Gargoyleosaurus or later, mid-Cretaceous forms, indicative of early feeding variability among the North American ankylosaurs. Most of the Aptian-Albian species exhibit toothed premaxillae (but see Peloroplites Carpenter et al. 2008), with either a narrow (Silvisaurus [Figure 5B]), or relatively wide, trapezoidal muzzle (Pawpawsaurus [Figure 5(C)], Peloroplites). In contrast, Campanian-Maastrichtian nodosaurids from North America (Edmontonia, Panoplosaurus) are characterized by a relatively wide and edentulous muzzle with highly variable outline. The type specimen of Panoplosaurus (CMN 2759) has a robust and rectangular muzzle. In specimens referred to Edmontonia, at least two different muzzle types can be distinguished (compare Figure 5(E) and (F)). Whereas the first 
morphotype (ROM 1215, TMP 98.98.01, TMP 2000.12.158) is smooth and rounded with relatively narrow nasal processes, the other one is massive and trapezoidal with wide and ornamented nasal processes (e.g. CMN 8531, USNM 11868, TMP 1983.25.2, AMNH 5381).

Direct evidence for muzzle shape in European ankylosaurs is only known in the Late Cretaceous Hungarosaurus (Figure 5(D)). This taxon is characterized by a relatively narrow and rounded muzzle with a lateroventral cutting edge and teeth, and, in contrast to most other ankylosaurs, the anterior edge of the premaxillae is not straight but crenulated, forming a thin, uneven margin. In other European forms (Sarcolestes, Anoplosaurus, Europelta,

Struthiosaurus), muzzle width can be roughly estimated based on the shape of the symphyseal part of the dentary. In all of these forms, the symphyseal region is lateromedially narrow, and either lacking (Sarcolestes, Anoplosaurus) or having (Europelta, Struthiosaurus) a short edentulous articulation surface for the predentary (Galton 1983; Pereda-Suberbiola et al. 1995; Pereda-Suberbiola and Galton 2001; Kirkland et al. 2013). This condition suggests that the muzzle was relatively narrow in early forms but became slightly wider in Late Cretaceous species. The edentulous, wide-beaked forms, as seen in the North American and Asian record, are apparently missing from the European ankylosaurian fauna.

\subsection{Quadrate-articular joint}

In many ankylosaurs, especially nodosaurids (e.g., Sarcolestes, Gargoyleosaurus, Peloroplites, Sauropelta, Hungarosaurus, Edmontonia USNM 11868) and some ankylosaurids (Gastonia DMNH 50191, Pinacosaurus Hill et al. 2003), the oval mandibular glenoid faces slightly medially, and is subtly longest anteroposteriorly. In these forms, the distal articular surface of the quadrate — particularly the medial condyle—is robust and anteroposteriorly elongate. By contrast, the glenoid of some advanced forms (e.g., Euoplocephalus AMNH 5405, Saichania PIN 3142/250, Ankylosaurus AMNH 5214) is 
mediolaterally elongate and articulates with the anteroposteriorly short, mediolaterally wide

distal articular end of the quadrate. The quadrate-articular joint of Edmontonia (ROM 1215)

slightly differs from that of other ankylosaurs. In this form, the glenoid is oriented

anterolaterally-posteromedially, and the medial quadrate condyle is elongate and more

anteriorly positioned than the lateral one. This feature results in an unusual jaw joint, with the anterior part of the quadrate medial condyle almost being excluded from articulation with the glenoid. This configuration might be related to limited anteroposterior movement of the mandible, as suggested by the orientation of dental microstriae (Mallon and Anderson 2014a).

In both Euoplocephalus (Rybczynski and Vickaryous 2001) and Hungarosaurus (Ösi et al. 2014a), the glenoid facilitated some anteroposterior movement (at least 5-10 mm, based on observed dental microstriae of AMNH 5405) of the mandible during occlusion. In Euoplocephalus (AMNH 5405) the oval distal end of the quadrate is mediolaterally elongate, and the glenoid is correspondingly mediolaterally elongate and perpendicular to the lateral surface of the mandible (Rybczynski and Vickaryous 2001). In Hungarosaurus, the distal quadrate articulation is more rounded and relatively longer anteroposteriorly than that of Euoplocephalus. Even so, the glenoid permitted 5-6 mm of anteroposterior movement of the mandible, resulting in a palinal jaw movement (Ösi et al. 2014a). Thus, it is not the specific shape, but the anteroposterior length of the glenoid relative to that of the quadrate condyles, that relates to the potential for anteroposterior jaw movement.

In all ankylosaurs, the jaw joint is placed ventral to the occlusal plane. There also appears to be a positive correlation between the depression of the jaw joint and the height of the coronoid process, as demonstrated in mammals (Maynard-Smith and Savage 1959; Smith 1993) and crocodyliforms (Ösi and Weishampel 2009). The jaw joint is particularly well depressed, and the coronoid process is especially well-developed, in nodosaurids, such as 
Animantarx, Sauropelta, Edmontonia and Hungarosaurus. This condition corresponds to a higher relative bite force in these forms (Mallon and Anderson, 2014b).

\subsection{Intermandibular joint}

The symphyseal surface of the dentary in ankylosaurs is moderately long, anteriorly tapering, and oval, with a vertical surface ornamented either by small pits (e.g. Edmontonia ROM 1215) or horizontal grooves (Hungarosaurus, Ankylosaurus). The predentary is a single, crescentric, mediolaterally long bone that connects the symphyseal ends of the two dentaries at their anterodorsal, anteroventral and laterodorsal margins. It is known only in a few ankylosaurs (e.g. Panoplosaurus CMN 2759, Pinacosaurus ZPAL Mg D-II/1, Euoplocephalus AMNH 5405) and even less is known about the mobility of the dentarypredentary joint (Vickaryous et al. 2004). The predentary articulation on the dentary, however, may be informative of the function of this joint (Nabavizadeh and Weishampel in press). Some differences exist between the edentulous anterior end of the mandibles of nodosaurids and ankylosaurids. In Euoplocephalus (AMNH 5405, TMP 1980.16.1685, Figure 7(A)), Ankylosaurus (AMNH 5214), Pinacosaurus (IGM 100/1014, Hill et al. 2003), Saichania (PIN 3142/250), Tarchia (INBR 21004, Miles and Miles 2009) and probably other ankylosaurids, the anterodorsal margin of the dentary is bordered from beneath by a deep and irregular groove. This groove is also seen in Gastonia (DMNH 53025) and Shamosaurus (PIN $3779 / 2$ ), although it is shallower, elongate and rugose, and the symphyseal joint is more massive in these basal ankylosaurids. This groove accommodates the prominent crest present on the medial side of the predentary. In nodosaurids (e.g., Sauropelta (AMNH 3032), Animantarx (Carpenter et al. 1999), Edmontonia longiceps (CMN 8531), Panoplosaurus (CMN 2759), or Hungarosaurus (MTM 2007.25.2, Figure 7(B)), the dentary does not bear a deep groove, but a few foramina occur along the anteroventral margin of the crest-like 
edentulous margin of the dentary, and this margin attaches to the posterior groove of the predentary. This edentulous margin is quite thick in Edmontonia (ROM 1215) and bears a shallow groove in TMP 98.98.01.

\subsection{Dentition}

The dentition of most ankylosaurs is homodont, though in some forms (e.g. Gargoyleosaurus) the premaxillary, maxillary, and dentary teeth show subtle morphological differences. Ankylosaur teeth are labiolingually compressed and phylliform, with an apical cusp and a series of secondary cusps along the mesial and distal edges (Coombs 1990).

Nodosaurid teeth (Figure 7(C)) are generally larger in absolute size (e.g. greatest mesiodistal crown width in Hungarosaurus [MTM 2007.25.2] 9-10 mm; Sauropelta [YPM VP 005528]:

9 mm; Edmontonia [TMP 98.98.01]: 10-11 mm; Europelta [FCPTD/MAP AR-1-325/10] 17.5 $\mathrm{mm}$ ) than those of ankylosaurids (e.g. Pinacosaurus [ZPAL Mg D-II/1]: 4-5 mm [Figure 7(D)]; Euoplocephalus [AMNH 5405]: 3-5 mm (Rybzynski and Vickaryous 2001); Saichania [PIN 3142/250]: 7-8 mm). Nodosaurid teeth are more blade-like and usually more complex than the cusp-like teeth of ankylosaurids (Mallon and Anderson 2014a) in having a larger crown, a rough enamel surface, crenelated cingulum and fluting that is confluent with the grooves of the marginal cusps (Coombs 1990, Figure 7(C)).

\subsection{Tooth wear analysis}

Wear facets on ankylosaur teeth are highly variable, and macrowear patterns differ markedly between nodosaurids and ankylosaurids. Whereas nodosaurid wear facets are usually more extensive and steeply inclined, those of ankylosaurids are smaller low-angled, and typically restricted to the apical region of the crown (for exceptions see Rybczynski and Vickaryous 
2001; Mallon and Anderson 2014a, and results below). These wear differences reflect underlying differences in shape-constrained function (Mallon and Anderson 2014a).

\subsubsection{Nodosaurids}

The record of nodosaurid tooth wear is comparatively poor (Table 2). The earliest record is in the Late Jurassic Gargoyleosaurus which exhibits an unusual wear pattern (Figure 8(A), Figure 8 (B)). Three upper and three lower teeth bearing wear facets are known in this

genus. Wear facets on the upper, slightly distally curved teeth have irregular, not smooth Törölt: are surface, mainly situated apically and along the mesial carina (Figure $8(\mathrm{~A})$, Figure 8 (B)). The labial surfaces near the bases of two of the maxillary teeth are also slightly worn (Figure 9(A)). The enamel-dentine interface (EDI) is obscured by locally fractured enamel. The three preserved dentary teeth possess labially positioned, steep wear facets that are flat but not as extensive as in Late Cretaceous forms (e.g. Hungarosaurus, Edmontonia). On the $20^{\text {th }}$ right dentary tooth, the wear facet extends from the apex to the base of the crown in an elongate, slightly concave surface exposing the underlying dentine (Figure 9(B)). The EDI is flush along most of the wear facet, but slightly stepped basally. Large, rough pits are relatively frequent, and scratches $>1 \mathrm{~mm}$ long are oriented apicobasally. Among Early Cretaceous nodosaurids, only specimens of Sauropelta (Ostrom 1970; Galton 1983) and Silvisaurus (Eaton 1960) show in situ fully erupted, functional teeth with wear facets. In Sauropelta, some isolated but associated teeth (e.g. YPM. VP. 005350, VP. 005351, VP. 005367, VP. 005526, VP. 005527) bear significant attritional wear (Figure 9(E-H)). In all cases, the cingulum of the working side is extensively worn, producing a steep facet. Two of these teeth (YPM. VP. 005350, VP. 005526) have steep apical wear as well. Early apical wear (YPM. VP. 005526) results in the erosion of only some cusps (Figure 9(F)), and later apical wear produces a more extensive and low-angled facet (YPM. VP. 5351, VP. 5527, Figure 
$9(G))$. Wear facets (both apically and on the cingulum) occur on either the distal or mesial sides of the crown and are rarely present in the central part of the apex/cingulum. These wear facets show great similarity to those of Edmontonia (ROM 1215, see below).

In the Early Cretaceous Silvisaurus wear is present on one of the posterior teeth of the left mandible of UKMNH 10296 (Figure 8(C), Figure 8(D); Eaton 1960:fig. 6B). This wear facet is quite similar to the extensive, bowl-like facets preserved on the teeth of Hungarosaurus (Ösi et al. 2014a). It forms a relatively large (up to $70 \%$ of the labial crown surface), smooth surface that is slightly concave basally where the cingulum is eroded. Microwear features on this tooth are presently unknown.

Most of the teeth of the Albian Europelta are in very poor condition (Kirkland et al. 2013), and wear patterns cannot be observed, but some teeth (e.g. FCPTD/MAP AR-1-324, AR-1325) show some wear (Figure 9(C), Figure 9(D)). Smaller apical wear facets occur along the denticulate margin (AR-1-325/10), and steep, slightly oblique wear facets are present either on the distal or mesial sides of the tooth (AR-1-417/10). Since the surfaces of these teeth are in a very poor condition, microwear cannot be observed.

Wear facets are most prevalent among Late Cretaceous nodosaurids. Tooth wear in the Santonian Hungarosaurus has been studied by Ösi et al. (2014a). As in Scelidosaurus (Barrett 2001), the upper and lower teeth show markedly different wear patterns. Wear facets on the upper teeth are mainly found apically, and are low angled and not as extensive basally as those on the lower teeth, covering approximately $20-40 \%$ of the lingual crown surface. Lower wear facets are more extensive, steeply inclined and, in some cases, slightly concave, bowllike surfaces covering almost $70 \%$ of the labial crown surface (Figure $8(\mathrm{E})$, Figure $8(\mathrm{~F})$ ). The EDI is flush distally but stepped mesially on most of the lower teeth. Scratches are usually apicobasally oriented on the apical half of the facet (Figure $9(\mathrm{~J})$ ), and mesiobasally and 
apicodistally oriented (at angles of $25^{\circ}$ to $40^{\circ}$ relative to the horizontal plane) where the facet

has eroded the cingulum (Figure $9(\underline{K})$ ).

Dental wear in the most wide-spread European ankylosaur Struthiosaurus have been reported

in some specimens. Nopcsa (1929) mentioned some wear pattern on the teeth of S. austriacus.

One of these teeth bears some apical wear and some steep wear on the cingulum (PIUW

2349/105b) occurs as well. Two teeth (UM2 OLD-18 CV, OLD-19 CV) referred to $S$.

Törölt: J

Formázott: Betütípus: Dölt

Formázott: Betütípus: Dőlt

Formázott: Betűtípus: Dőlt

Törölt: Struthiosaurus

languedocensis (Garcia and Pereda-Suberbiola 2003) bear informative wear facets. The wear facet on UM2 OLD-19 CV, covering approximately the $30 \%$ of the crown, is steeply inclined (ca. $60^{\circ}$ relative to the horizontal plane) and extends from the apex to the base of the cingulum (Figure 9(I)). The apex and the mesial or distal cusps are also eroded, exposing the underlying dentine. Steep wear is either mesially or distally positioned on the lingual or labial side of the crown. Scratch orientation is unknown. Recently, Csiki et al. (2016: fig. 12P) published on a nodosaurid tooth (LPB R.22.88) from the Late Cretaceous of Romania that shows steeply inclined wear along its labial or lingual surfaces, and the three preserved cusps are also worn apically, as in S. languedocensis.

The type of Edmontonia longiceps (CMN 8531) possesses two left and two right posterior functional maxillary teeth. The right teeth bear apical wear and most denticles are also worn on their mesial and distal sides. On one of these teeth, the wear facet is steep and extends to the base of the crown (Figure 12(D)). The lingual side of the crown, having an originally coarse enamel surface, is smooth but the dentine is not exposed. The EDI is best visible on the worn cingulum, where the apical junction is flush and the basal interface is stepped.

Microwear pits are rare and triangular; scratches are fine, usually shorter than $1 \mathrm{~mm}$, and nonuniformly oriented.

In Edmontonia specimen ROM 1215, the posterior maxillary teeth are significantly worn (Russell 1940; Coombs 1990, Figure 8(I), Figure 8(J)). Mallon and Anderson (2014a) gave a 
detailed description of tooth wear in this specimen, thus only some comments are added here. Every second tooth in the left series $10-15$ is markedly worn (Figure 8(I), Figure 8(J)), a phenomenon resulting from the alternating pattern of tooth replacement. As noted by Mallon and Anderson (2014a), early stage tooth wear (e.g. the left $11^{\text {th }}$ maxillary tooth) results in small, subvertical $\left(40^{\circ}-60^{\circ}\right.$ relative to the horizontal plane) facets, whereas later stage wear (e.g. left $14^{\text {th }}$ maxillary tooth; Figure $9(\mathrm{~L})$, Figure 10(B), Figure 10(C)) results in a larger and more nearly horizontal facet $\left(20^{\circ}-30^{\circ}\right.$ relative to the horizontal plane $)$. Early-stage wear facets are either apically or mesially arranged, with the mesial facet typically extending more basally on the crown, and having a smooth surface with rare pits (Figure 9(M)). Late-stage wear facets may be slightly concave, and the exposed dentine bears many triangular pits (Figure 10(B), Figure 10(C)). Scratches (> $1 \mathrm{~mm}$ long) are usually apicomesially-distobasally oriented. A stepped EDI occurs on the basal and distal sides of the wear facets.

One isolated lower tooth from ROM 1215 (Figure 10(E)) shows a rounded apical wear facet with exposed dentine that extends labially into a steeply inclined facet. This labial facet has an oblique, most probably mesiobasal-apicodistal orientation with scratches over $1 \mathrm{~mm}$ in length oriented in the same direction. Triangular pits are numerous on the exposed dentine.

Right maxillary teeth 13-16 (Figure 8(G), Figure 8(H)) of Edmontonia specimen TMP 98.98.01 show heavy wear that slightly differs from that seen in ROM 1215. Whereas the wear facet on the $13^{\text {th }}$ tooth is mainly located on the distal carina, forming a deep, lobe-like surface, those of teeth 15 and 16 are apically situated, planar, low-angled, and face labially, but are less extensive than those on the posterior teeth of ROM 1215. The eroded dentine surfaces bear many pits; however, scratches $>1 \mathrm{~mm}$ long are uncommon. None of the cingula or labial tooth surfaces are eroded, in contrast to ROM 1215 or CMN 8531. Opposite maxillary tooth 13 , dentary tooth 16 exhibits similar lobe-like wear on the mesial carina. This type of wear is not typical in ankylosaurs and is probably related to malocclusion (Figure 
$8(\mathrm{G})$, Figure $8(\mathrm{H})$, Figure $10 \mathrm{C})$. Steeply inclined labial wear is only observed on the $9^{\text {th }}$ dentary tooth, especially on the cingulum, and on the left maxillary teeth 4 and 6-8.

One isolated tooth associated with the type of Panoplosaurus mirus (CMN 2759) shows steeply inclined wear apically (Figure $10(\mathrm{G})$ ) and on the cingulum. Scratches $>1 \mathrm{~mm}$ are rare and show no preferred orientation.

\subsubsection{Ankylosaurids}

The record of in situ dentition in ankylosaurids is more complete than in nodosaurids (Table 2). Among Early Cretaceous forms, Gobisaurus (HGM 41HIII-0002, described as 'Zhongyuansaurus' by Xu et al. 2007 and referred to as Gobisaurus by Arbour and Currie 2016), bears teeth in the right maxilla (Xu et al. 2007) that appear minimally worn at most. The type specimen of Gobisaurus (IVPP V12563) has eight teeth in the left and five teeth in the right maxilla (Vickaryous et al. 2001). Apical wear facets are present on a few teeth (e.g. anteriormost right tooth with a small, lingually facing, low-angled apical facet).

Among Late Cretaceous ankylosaurids, the Turonian-Coniacian Maleevus has at least two worn maxillary teeth (Figure $8(\mathrm{M})$, Figure $8(\mathrm{~N})$ ). Although the taxonomic status of this ankylosaur is problematic (PIN 554, regarded as nomen dubium by Arbour and Currie 2016), the presence of worn ankylosaur teeth from this underrepresented period is quite important. Wear facets on the $6^{\text {th }}$ left maxillary tooth are apically, linguodistally and mesiodistally oriented (Figure 11(B)). Apical wear, probably representing abrasive wear, is shallow, smooth, and rounded. Steep linguodistal wear extends basally on the crown with a few vertically oriented scratches. The EDI cannot be observed because the enamel is poorly preserved. A linguomesially positioned, slightly concave, steeply inclined wear facet occurs on a right anterior maxillary tooth. 
The Santonian Pinacosaurus grangeri (ZPAL Mg D-II/1) has well preserved teeth both in the upper and lower jaws (Figure 8(Q), Figure 8(S)). In contrast to most ankylosaurs, it does not Törölt: show any indication of attritional wear, a phenomenon that might be related to its juvenile ontogenetic status. Minimal wear occurs on the apices of some mesial and distal cusps, which is likely due to food abrasion (Figure 11(A)).

Teeth of the Campanian Saichania (MPC 100/151; PIN 3142/250 areferred specimen to Tarchia gigantea Maryanska, 1977, see Arbour et al. 2014a) provide clear evidence for tooth wear (Barrett 2001). In PIN 3142/250, wear facets are generally apically positioned and subcircular, with the mesial and distal cusps apically eroded and with the dentine exposed in many cases (Figure 8(O), Figure 8(P), Figure 11(C), Figure 11(D)). Wear facets are usually low-angled; steeper $\left(>45^{\circ}\right)$ facets are rare. The lingual cingulum of the maxillary and the labial cingulum of the dentary teeth, and the labial/lingual sides of the crowns, are unworn. Some teeth also show signs of slight abrasion on the enamel. Both scratches and pits frequently occur on worn facets. Some scratches are $>1 \mathrm{~mm}$ and many are mesiodistally oriented. Arbour et al. (2014a) referred Minotaurasaurus ramachandrani Miles and Miles, 2009 to Tarchia kielanae (INBR 21004). Teeth of this specimen are nicely preserved and show some wear. Wear facets are similar to those in Saichania (PIN 3142/250) in being small and apically occurring.

In contrast to Asian ankylosaurids, North American forms show markedly different wear patterns. Many teeth of Euoplocephalus (AMNH 5405, ROM 1930) are strongly worn (Rybczynski and Vickaryous 2001; (Figure 8(K), Figure 8(L)). Wear facets on the right maxillary teeth of AMNH 5405 are steeply inclined and slightly concave, extending from the crown apex to the shallow cingulum (Figure 8(K), Figure 8(L), Figure 11(G), Figure 11(H)). The angle of the facets relative to the horizontal plane decreases as the extent of tooth erosion increases, as in Edmontonia (ROM 1215). In contrast to Hungarosaurus, wear facets on the 
maxillary teeth of Euoplocephalus are rather steeply inclined, sometimes slightly concave.

Highly eroded crowns with extensive wear facets are present in the case of the anterior right maxillary teeth (Figure 11(G)). Here many scratches are $>1 \mathrm{~mm}$ long and mesiodistally oriented. The eroded dentine surfaces bear many pits. Many deep, subvertical scratches occur on the last four maxillary teeth. The EDI cannot be observed well on all the worn teeth of AMNH 5405. Some of the posterior teeth (e.g. the $14^{\text {th }}$ ) of ROM 1930 show lingual wear facets. This facet is similar to those on the right maxillary teeth of AMNH 5405 in being steep and slightly concave. Microwear features are unobservable on ROM 1930.

Specimen TMP 1997.132.1, orignally referred to Euoplocephalus by Vickaryous and Russell (2003) and later assigned to Anodontosaurus (Arbour and Currie 2013), also have a few teeth, but they seem to be not fully erupted and are completely unworn.

The only other North American ankylosaurid with dental wear is Ankylosaurus (CMN 8880). A single, associated tooth bears steep wear facets on the cusps of the ?mesial carina and on the ?mesial part of the cingulum (Figure 11(E), Figure 11(F)). The dentine is deeply eroded between the labial and lingual enamel margins of the cusps (a groove separates the cuspidate margin from the body of the crown, see Figure 11(E)), and the eroded surfaces of the individual cusps are confluent, bearing some subvertical scratches. Wear on the cingulum is very similar to that on the isolated tooth of Panoplosaurus (CMN 2759). The apical region is only slightly worn, showing mesiodistally oriented scratches along the lingual enamel surface.

\subsubsection{Comparison of microwear features}

In nodosaurids, pit percentage is usually lower than $40 \%$, with only one of the associated teeth of Panoplosaurus (CMN 2759, Figure 12(C)) showing a higher pit ratio. Although based only on two micrographs, Panoplosaurus (CMN 2759) has the highest pit percentage $(58 \%)$ and the second shortest scratches among all the ankylosaurs. There is generally neither 
positive nor negative correlation between scratch number and scratch width or between scratch width and length (see numbers in Table 3). Scratch width is similar in most taxa; only Euoplocephalus and Hungarosaurus (Figure 12(A), Figure 12(B)) have slightly higher mean scratch width values. Euoplocephalus (AMNH 5405, seven micrographs, Figure 13(E), Figure 13(F)) has a lower mean pit ratio (32\%) than Saichania (51\%, PIN 3142/250, three micrographs, Figure 13C) and Maleevus (56\% PIN 544 1-2, two micrographs, Figure 13(B)); a considerable difference between North American and Asian forms that is in line with the different macrowear patterns observed in these taxa. Ankylosaurus (CMN 8880) is represented by a single tooth (Figure 13(D)) with a pit ratio of $43 \%$. Scratch length and width does not differ appreciably between ankylosaurids and nodosaurids, and regarding the microwear patterns in general, Mallon and Anderson (2014a) found no significant differences between North American Late Cretaceous ankylosaurids and nodosaurids. Hungarosaurus and Euoplocephalus, however, have a much higher number of elongate scratches (over $1 \mathrm{~mm}$ in length) than the other ankylosaurs. Gargoyleosaurus (Figure 13(G), Figure 13(H)) has a low pit number (32\%), relatively long scratches and the lowest pit size among the studied forms, making it most similar to forms with complex jaw movement.

Interestingly, some important differences occur between the two specimens of Edmontonia rugosidens (TMP 98.98.01. and ROM 1215). In ROM 1215 (Figure 12(G)), the pit number is lower (31\%) than in TMP 98.98.01 (43\%), whereas scratches are almost two times longer and pits are 1.5 times wider. In the type of Edmontonia longiceps (CMN 8531), only two micrographs (Figure 12(D)) could be evaluated, indicating a very low pit percentage (18\%). Microwear features from different (i.e. anterior and posterior) regions of the tooth row of a single specimen are available in Edmontonia rugosidens (TMP 98.98.01), Hungarosaurus (MTM 2007.25.2), Euoplocephalus (AMNH 5405), and Saichania (PIN 3142 250). However, none of the wear features show an appreciable change along the tooth row. Only scratch 
length values appear to be slightly higher in the posterior teeth of Euoplocephalus compared to the anterior ones, but even in this taxon there are too few specimens to draw firm conclusions.

These data further support the previous interpretations that wear pattern in ankylosaurs is not as uniform as those seen in e.g. hadrosaurs and ceratopsids, and ankylosaurs have more variable microwear values (e.g. scratch/pit ratio) than to those seen in the other herbivorous forms (Mallon and Anderson 2014a).

\subsection{Jaw adductor muscles}

Jaw adductors have already been reconstructed both in nodosaurids (Holliday 2009; Ösi et al. 2014a) and ankylosaurids (Haas 1969. Coombs 1971. Carpenter et al. 2011) (see comparison of muscle origin and insertion surfaces in Supplementary data 4).

The cranial adductor fossa of ankylosaurs is a dorsoventrally deep chamber bordered posteriorly by the dorsoventrally elongate, slightly anteriorly oriented quadrate shaft, dorsally by the squamosal and postorbital, laterally by the orbital region, and medially by the braincase and pterygoid (Figure 14(A), Figure 14(B)). The dorsal part of this cavity bears the origin for the external adductors (M. adductor mandibulae externus profundus (MAMEP), M. adductor mandibulae externus medialis (MAMEM), M. adductor mandibulae externus superficialis (MAMES)), and that of M. pseudotemporalis superficialis (MPSS) (Figure 14(A), Figure 14(B)), and is morphologically conservative within the group. The dorsal surface of the temporal fossa (i.e. the ventral surface of the skull roof) can be observed only in some well preserved and sufficiently prepared specimens (e.g. ankylosaurids: Shamosaurus (PIN 3779/2), Pinacosaurus (Zpal-MgD II/1), Saichania (PIN 3142 250, Figure 14(B)) and Euoplocephalus (AMNH 5405); nodosaurids: Edmontonia (ROM 1215, Figure 14(A)), and partly in Struthiosaurus transylvanicus (NHM R4966)). This region is rugose, but usually 
does not bear any marked crests or muscle scars. Therefore, determining a more precise origin for these muscles is controversial (Supplementary data 4). In the case of M. pseudotemporalis profundus (MPSP) different origins have been reconstructed in different taxa (see Haas 1969; Holliday 2009; Carpenter et al. 2011, Supplementary data 4), but these regions, if available, do not provide information about the size of the origin. The origin of the M. adductor mandibulae posterior (MAMP) is the anterior (Carpenter et al. 2011) or lateral (Holliday 2009) side of the quadrate (Figure 14(A), Figure 14(B)). These areas are similar in most ankylosaurs and do not bear distinct scars or aponeuroses for muscular attachment.

Based on the size of the muscular origins and insertions, it is clear that the pterygoid muscles (M. pterygoideus dorsalis (MPTD), M. pterygoideus ventralis (MPTV)), in ankylosaurs had relatively lower mass than in crocodyliforms, so their role was probably less important in jaw closure. Nevertheless, the pterygoids apparently differ in relative size and orientation between nodosaurids and ankylosaurids, suggesting some difference in the mass of these internal adductors (Figure 14(A), Figure 14(B)). In Euoplocephalus and Gobisaurus (and in many other ankylosaurids Figure 14(B)), the pterygoids are almost vertically oriented and relatively narrow. In early nodosaurids (e.g. Gargoyleosaurus, Gastonia), the pterygoid complex is not yet well developed anteroposteriorly and mediolaterally but, in later forms (e.g. Silvisaurus, Pawpawsaurus, Edmontonia, Figure 14(A)), they are much wider, with more robust lateral wings, and anteroposteriorly more expanded than in basal forms, reaching the level of the distal quadrate condyles. This suggests relatively more developed pterygoid muscles (MPT) in later nodosaurids than in ankylosaurids.

Muscle insertions on the mandible appear to be more informative than those on the skull (Figure 14(C-F)). Comparison of the mandibular adductor fossa among ankylosaurs provides evidence for a relatively more developed jaw adductor musculature in nodosaurids than in ankylosaurids. The mandibular adductor chamber was larger and the coronoid process 
relatively higher (Figure 14(C), Figure 14(D)) in many nodosaurids than in ankylosaurids, implying differences in muscle size and/or in the angle at which jaw adductors attached to the coronoid process. As these features largely determine the relative force and speed of muscle action (as in extant crocodiles [Endo et al. 2002; Mueller-Töwe 2006] or mammals [MaynardFormázott: Betütípus: Nem Dőlt Smith and Savage 1959; Smith 1993]), they most probably reflect a more efficient jaw adductor system in nodosaurids than in most ankylosaurids (Mallon and Anderson 2015).

\section{Discusison}

\subsection{Cranial characters related to the mode of feeding}

In many herbivorous mammals, the width of the muzzle correlates with both foraging time and diet (Owen-Smith 1979; Owen-Smith 1982; Owen-Smith 1985; Owen-Smith 1988; Solounias et al. 1988; Dompierre and Churcher 1996, but see Tennant and MacLeod 2014). In ruminants, for example, muzzle width is an important indicator of grazing vs. browsing habits (IIIius and Gordon 1987; Gordon and IIIius 1988). Whereas broad muzzles can crop larger amounts of food (e.g. dry grass of low nutritional value) from a flat surface per bite (Gordon and Illius 1988; Owen-Smith 1988), a narrow muzzle permits the selection of more nutritious parts for consumption (Jarman 1974; Owen-Smith 1982; Clutton-Brock and Harvey 1983; Janis and Ehrhardt 1988).

It is likely that ankylosaur muzzle shape also reflects feeding habits. Based on the available fossil record, the most conspicuous change in muzzle shape was a progressive widening sometime in the middle Late Cretaceous (Figure 6). Jurassic and mid-Cretaceous forms with narrow and pointed muzzles (Figure 5(A-C), Figure 6) were presumably selective feeders, akin to mammalian browsers (Jarman 1974; Shipley 1999). Most of the Late Cretaceous (Santonian-Maastrictian) forms (Figure 5(E-G), Figure 5(K), Figure 5(L), Figure 6) were less selective or adapted to bulk feeding on less nutritious food (ferns have been 
suggested: Weishampel and Norman 1989; Weishampel and Jianu 2000; Sander et al. 2010; Mallon and Anderson, 2014a; Mallon and Anderson, 2014b). The edentulous, wide-beaked forms of North America and Asia, are notably missing from the European record, possibly reflecting a lack of open habitats on the islands of the European archipelago (Csiki et al. 2015). Nevertheless, it has to be also noted that the European record is much less complete that that in North America and Asia (Ösi 2015).

Other cranial elements may also relate to ankylosaur feeding. A nearly complete hyobranchial apparatus has been described in Pinacosaurus grangeri (IGM 100/3186), and some articulated elements are also preserved in other taxa (e.g. Edmontonia AMNH 5381, Euoplocephalus AMNH 5405, Saichania MPC 100/151) (Maryanska 1977; Hill et al. 2015). The presence of these rarely fossilized elements, combined with the inferred relatively slow tooth replacement (Erickson 1996), implies that ankylosaurs had fleshy, muscular tongues that played a more important role in their feeding than previously thought (Hill et al. 2015). Although the degree of tongue protrusion and prehension in ankylosaurs is unknown, it is likely that, at least in Saichania and Pinacosaurus, lingual food manipulation was an important component of feeding that might also have included the ability to crop vegetation akin to a giraffe (Maryanska 1977; Carpenter 2012; Mallon and Anderson 2013; Hill et al. 2015). Thus, the presence of a fleshy tongue and lack of extensive tooth attrition in these ankylosaurids suggests that tongue function might have indeed been more complex than previously thought.

In ankylosaurs, the most convincing evidence for the previous existence of fleshy cheeks and chewing is the presence of cheek plates preserved in original position just lateral to the tooth rows in Panoplosaurus mirus (CMN 2759, Lambe 1919, Figure 7(E)) and in Edmontonia (AMNH 5381, Vickaryous 2006, Figure 7(F)). A larger, oval shaped, anteroposteriorly elongate plate occurs anteriorly, and few smaller elements occur posteriorly. 
These osteoderms are fused neither to the mandible nor to the maxilla (Vickaryous 2006), suggesting some limited mobility within the bucca. These elements unambiguously demonstrate that a fleshy bucca, embedding these osteoderms, covered the tooth rows to prevent lateral food loss during chewing.

The lack of cheek plates in the exceptionally preserved specimens of Saichania and Pinacosaurus deserves further consideration. In the Pinacosaurus specimen IGM 100/3186, where the delicate hyobranchial apparatus is preserved intact (Hill et al. 2015), the lack of cheek plates hardly seems attributable to preservational bias. Instead, it seems much more likely that at least these ankylosaurids genuinely lacked cheek plates, perhaps because they did not chew like Edmontonia or Panoplosaurus. This hypothesis would in line with the markedly different wear regimes between ankylosaurids and nodosaurids mentioned above. On the other hand, however, the type of 'Minotaurasaurus ramachandrani' Miles and Miles, 2009 (INBR 21004 later referred to as Tarchia kielanae by Arbour et al. (2014a) has a pair of small, unfused osteoderms present just below the orbits. Whether these elements are homologous with the posterior cheek plates of the above mentioned nodosaurids or not is hard to decide. Nevertheless, in INBR 21004 these bones are in the level of the last three maxillary teeth suggesting that the bucca might have been not as extended anteriorly as in Edmontonia or Panoplosaurus. An alternative hypothesis is that an anteriorly extended fleshy bucca was present in INBR 21004 (and in other ankylosaurids as well), but they did not embed extensive cheek plates.

\subsection{The process of tooth-tooth contact in chewing}

In Gargoyleosaurus parkpinorum, the earliest ankylosaur with dental wear, tooth occlusion cannot be confirmed. The labially oriented wear facets on the lower teeth are likely the result of food abrasion rather than precise tooth occlusion (Figure 15(A), Figure 15(F)). 
Alternatively, some incidental or local occlusion of the upper and lower teeth can produce similar, weak wear facets.

The earliest unambiguous evidence for precise dental occlusion can be demonstrated in the Early Cretaceous Sauropelta. Tooth wear in this form clearly indicates some sort of occlusion between the upper and lower teeth (Figure 15(B)). Since information on microscratch orientation is currently unavailable, it is unclear how the upper and lower teeth of Sauropelta occluded. Nevertheless, the shape and position of the wear facets suggest that the main direction of the power stroke was orthal (Figure 15(B)). There might have been some anteroposterior component of jaw movement but this cannnot be supported at the moment. The relatively low-angled wear facet on one maxillary tooth (YPM 5527) suggests that the plane of occlusion was offset from the vertical plane, a phenomenon also seen in the basal thyreophoran Scelidosaurus (Barrett 2001) and the nodosaurid Hungarosaurus (Ösi et al. 2014a).

The extensive, bowl-like wear facet on one of the posterior dentary teeth of Silvisaurus suggests tooth occlusion in at least this one case. This wear facet is quite similar to those on the lower teeth of Hungarosaurus, but because the other lower teeth do not show extensive wear, and the upper tooth crowns seem to be complete and unworn, only localized tooth occlusion can be inferred in Silvisaurus.

The steep, slightly oblique wear facets on teeth in the Early Cretaceous Europelta (e.g. FCPTD/MAP AR-1-325/10) could have been produced by tooth-tooth occlusion. However, the few teeth with this wear pattern, and their poor condition, obscure further details. Sophisticated dental occlusion (Figure 15(C), Figure 15(D)) among Late Cretaceous nodosaurids can be demonstrated in Hungarosaurus, Edmontonia, and possibly in Panoplosaurus on the basis of tooth wear, although tooth occlusion was evidently accomplished in different ways in these taxa. Tooth wear in Hungarosaurus reveals attritional 
facets that vary in their orientation relative to the vertical plane (Figure 15(C), Figure 15(D)). Scratch orientation indicates a palinal power stroke (see below) (Ösi et al. 2014a, Figure 15(D), Figure 15(E), Figure 15(G)). Struthiosaurus languedocensis appears to have possessed a similar type of occlusion.

In Edmontonia (CMN 8531, ROM 1215) the extensive wear facets (Figure 8(I), Figure 8(J), (Figure 9(L), Figure 9(M)) were certainly formed by tooth occlusion. The vertically oriented scratches present on the upper teeth indicate orthal jaw closure, whereas the mesiobasalapicodistally oriented scratches (Figure 10(A-C), Figure 10(E)) suggest a palinal power stroke (Mallon and Anderson 2014a). The slightly different wear pattern of Edmontonia specimen TMP 98.98.01 suggests a simple orthal shearing without any significant anteroposterior movement of the lower jaw (Figure 15(B)). Precise tooth occlusion is suggested for Panoplosaurus (CMN 2759) as well, though more data are needed to confirm this hypothesis and to elucidate the details of the dental function during jaw closure. Among ankylosaurids, tooth occlusion is present in Euoplocephalus (Rybczynski and Vickaryous 2001) and possibly Ankylosaurus. In Euoplocephalus, the presence of steeply inclined and extensive wear facets along the tooth row (AMNH 5405, Figure 8(K), Figure $8(\mathrm{~L}))$ suggests precise tooth occlusion, and the mesiodistal orientation of many scratches (Mallon and Anderson 2014a) clearly indicates a palinal power stroke (Rybczynski and Vickaryous 2001, Figure 15(G)). Wear features in Ankylosaurus (CMN 8880) suggest a similar capacity for tooth occlusion, but further evidence is needed.

In Asian ankylosaurids (e.g., Gobisaurus, Pinacosaurus spp., Saichania, Tarchia) tooth wear is either restricted to the apical cusps slightly exposing the underlying dentine, or it is more extensive basally as a smooth surface, yet does not penetrate the thin enamel. Steep wear facets, similar to those seen in nodosaurids, are present neither on lingual/labial sides of the crown, nor on the cingulum. In 'Maleevus disparoserratus', considered as a nomen dubium 
by Arbour and Currie (2016), two maxillary teeth show apical and minimal lingual wear, but

these facets are much less developed than those of nodosaurids with precise tooth occlusion. Wear typical of Asian ankylosaurids is most likely the result of food abrasion (Figure 15(A), Figure 15(F)) rather than habitual tooth occlusion. It is inferred that, in the lineage of Asian ankylosaurids (from Aptian to Maastrichtian taxa), food processing was devoid of precise tooth occlusion, and food was triturated by simple orthal pulping, similar to most extant lizards (Schwenk 2000).

\subsection{Jaw mechanism in ankylosaurs}

Craniomandibular and tooth wear features imply that ankylosaur jaw movement was not restricted to simple orthal pulping uniformly in all species, as traditionally assumed (Weishampel 1984; Galton 1986; King 1996; Hwang 2005). Variation in adductor musculature, jaw joint morphology, and tooth wear reveal at least three different jaw mechanisms during the evolution of Ankylosauria:

1) Orthal pulping. The main component of jaw action was orthal. The mandibular glenoid is anteroposteriorly short, preventing extensive motion in this plane. Teeth did not occlude (Figure 15(A), Figure 15(F)); only abrasive wear occurs on teeth. Origin surfaces of pterygoid muscles and insertion surfaces for external adductors were relatively small (low coronoid process), and partitioning of the MAME group was less developed than in ankylosaurs with more a complex jaw mechanism. Orthal pulping was typical of Asian ankylosaurids and probably in Gastonia as well.

2A) Local or incidental occlusion. The main component of the power stroke was orthal (Figure 15(A), Figure 15(F)). The mandibular glenoid is anteroposteriorly short, minimizing movement in this plane, but some mediolateral displacement or long axis rotation of the mandibles might have occurred. Local occlusion can be inferred for Gargoyleosaurus and 
Silvisaurus, where attritional wear is restricted to a few teeth. Local occlusion might also have been present in Europelta, given that few teeth show attritional facets.

2B) Tooth occlusion along the whole maxillary tooth row. In a few ankylosaurs, attritional wear occurs along the entire tooth row, but the position and orientation of wear facets together with EDI and scratch orientation shows that jaw closure was strictly orthal (Figure 15(B), Figure 15(F)). A mediolateral displacement or long axis rotation of the mandibles may have existed. The pterygoid external adductor musculature was well developed. Wear patterns indicate that this type of orthal shearing existed in Edmontonia (TMP 98.98.01) and possibly Panoplosaurus (CMN 2759) and Struthiosaurus, though more material is needed from the last two taxa to determine whether jaw closure was truly orthal or more complex.

3) Palinal movement. This is the most advanced jaw mechanism reported in ankylosaurs so far, consisting of two phases. In the first phase, simple orthal movement brought the teeth into occlusion (Figure 15(C), Figure 15(G)). The quadrate condyles were situated posteriorly in the mandibular glenoid. This type of mandibular movement is reflected in the near vertical orientation of microstriae. The second phase consisted of a palinal power stroke, pulling the mandible posteriorly and slightly dorsally with precise tooth occlusion (Figure 15(D), Figure $15(\mathrm{G})$ ). This phase of jaw movement produced slightly curved and oblique, mesiobasallyapicodistally oriented scratches on the teeth. This biphasal jaw mechanism was present in the nodosaurid Hungarosaurus, at least some specimens of Edmontonia (ROM 1215, Mallon and Anderson, 2014; CMN 8531), and might have already been present in Sauropelta as well. This mechanism has been demonstrated in the North American ankylosaurid Euoplocephalus (Rybzynski and Vickaryous 2001; Mallon and Anderson, 2014a) and possibly Ankylosaurus. In the latter taxon, the mesiodistally oriented scratches on a tooth associated with the skull of CMN 8880, and the anteroposteriorly elongate glenoid, support this hypothesis. 
The predentary-dentary joint of both nodosaurids and ankylosaurids allowed a mediolateral displacement and/or long axis rotation of the mandibular rami (Rybczynski and Vickaryous 2001; Ösi et al. 2014a). To achieve precise occlusion of the teeth, the complimentary work of the pterygoid and external adductor muscles was essential.

Contraction of the pterygoid muscles would have produced minimal medial rotation of the mandibles about their axes to bring the teeth into precise occlusion. Palinal movement of the mandibles, however, required exertion of the external mandibular adductors. Whether their work was alternating unilateral, as in mammals (Mills 1967; Crompton and Hiemae 1970), some heterodont crocodyliforms (Pol 2003; Ösi 2014), and possibly ceratopsids (Mallon and Anderson 2015), or bilateral, as extant crocodylians (Busbey 1989), is unknown at present.

\subsection{Evolution of key feeding specializations among thyreophorans}

The different types of thyreophoran tooth occlusion and jaw mechanics can be mapped onto existing phylogenetic trees (Supplementary data 5 and 6 based on Thompson et al. (2012) and Arbour and Currie (2016), respectively). In basal thyreophorans, such as in Scutellosaurus

(Colbert 1981) and Emausaurus (Haubold 1990), tooth occlusion was absent (Popowics and Fortelius 1997, Barrett 2001, Supplementary data 5). Scelidosaurus is the basalmost and earliest thyreophoran with precise tooth occlusion, and for which a puncture-crushing feeding mechanism has been demonstrated (Barrett 2001, Supplementary data 5 and 6). Among Törölt: Figure 16,17 stegosaurs (e.g. Huayangosaurus (Sereno and Dong 1992 and Stegosaurus Barrett 2001, DMNH 2818 A.Ö. pers. obs.)), local or incidental tooth-tooth contact occurred, but a wellcontrolled shearing bite along the length of the tooth row was absent (Supplementary data 5 and $)_{\text {. }}$

Törölt: Figure 16,17 Among nodosaurids, the coronoid process was already prominent in Early Cretaceous forms (Animantarx, Sauropelta, Silvisaurus), and a complex tooth crown with a rough enamel 
surface, crenelated cingulum, and fluting confluent with the grooves of the marginal cusps was widespread. Whereas dental occlusion appears to have been localized or incidental in the Late Jurassic Gargoyleosaurus, in Cretaceous nodosaurids it occurred more frequently (Figure 16). Unfortunately, the incompleteness of the fossil record and the problematic

Törölt: , 18 nodosaurid phylogeny prohibit optimization of a precise shearing bite.

Palinal jaw movement might have been present in many Cretaceous nodosaurids, but most likely evolved independently in various lineages (perhaps in some Early Cretaceous forms [Sauropelta], Late Cretaceous European forms [Hungarosaurus], and Late Cretaceous North American forms [Edmontonia ROM 1215, Panoplosaurus CMN 2759]) (Supplementary data 5 and 6, Figure 16), that is further supported by the most recent nodosaurid phylogeny of Arbour et al. (2016:fig. 1). In these forms, the coronoid process is high, the elongate mandibular glenoid allowed the lower jaws to shift anteroposteriorly, and the mandibular rami were capable of minimal long-axial rotation (Figure 16).

Dental occlusion and a complex jaw mechanism were generally absent among ankylosaurids (Figure 16), except for some Late Cretaceous North American forms (e.g., Euoplocephalus and Ankylosaurus), where a shearing bite and palinal movement of the lower jaws evolved independently of Nodosauridae. The minimal dental wear in the taxonomically dubious 'Maleevus' suggests that, in some basal Asian forms, local or incidental tooth occlusion might have occurred (Figure 8(M), Figure 8(N), Figure 11(B)). Ankylosaurids retained a low coronoid process and the muzzle became significantly wider both in Asian and North American Late Cretaceous forms (Figure, 16).

Törölt: 18

\subsection{Paleoecological inferences}

Our results demonstrate that several nodosaurids were able to render food with precise toothtooth occlusion, whereas most ankylosaurids processed food without precise occlusion. The 
North American Euoplocephalus (Rybzynski and Vickaryous 2001) and Ankylosaurus were possible exceptions among ankylosaurids, showing dental occlusion and, in case of the former taxon, a palinal jaw movement as well. What could be the reason for these markedly different feeding strategies? According to the most recent phylogenetic hypotheses (Thompson et al. 2012, Arbour and Currie 2016, Arbour et al. 2016), tooth occlusion and a palinal power stroke Törölt: The lack of phylogenetic constraint sugge

Törölt: sts that the occurrence of occured convergently in many lineages (including nodosaurids and ankylosaurids) suggesting that this functional novelty may correlate better with geography and ecology.

Törölt: Based on the geographical and temporal distribution of tooth wear patterns, precise dental occlusion may have been a crucial innovation in late Early Cretaceous (Sauropelta) to Late Cretaceous (Edmontonia, Panoplosaurus) North American nodosaurids and at least in some Late Cretaceous (and perhaps some Early Cretaceous) European nodosaurids (Hungarosaurus, and perhaps in Struthiosaurus). Since no cranial material of Asian Törölt: ? nodosaurids (Dongyangopelta, Sauroplites, Taohelong) is preserved, no information about their tooth wear is available. Among Asian and North American ankylosaurids, only the Late Cretaceous North American Euoplocephalus and Ankylosaurus provide evidence for dental occlusion (Anodontosaurus, Scolosaurus, Ziapelta have no functional teeth).

Bearing these observational limitations in mind, these data suggest that oral food processing with dental occlusion and biphasal jaw mechanism evolved in several North American ankylosaurids and nodosaurids, and in the European nodosaurids, but may not have existed in Asian representatives.

Differences in feeding strategies among ankylosaurs might be related to the different types of vegetation consumed by these low-level feeders on different landmasses. Climate reconstruction for the depositional environments of the Belly River and Edmonton groups in Alberta, Canada, where Edmontonia, Panoplosaurus, Euoplocephalus and Ankylosaurus are found, reveals that the climate was warm, subtropical/temperate monsoonal with occasional 
rainfalls, tropical storms and forest fires (Dodson 1971; Jarzen 1982; Wood et al. 1988;

Eberth et al. 1990; Noad 1993; Eberth and Hamblin 1993; Eberth 2005; Eberth 2015; Fricke et al. 2010; Brown et al. 2012). European ankylosaurs (Europelta, Hungarosaurus,

Struthiosaurus) lived on an archipelago during the Cretaceous (Csiki et al. 2015), where most of the islands experienced humid, subtropical and, in some cases, seasonally variable climate conditions (Astibia et al. 1999; Van Itterbeeck et al. 2004; Therrien 2005; Bodor and Baranyi 2012; Popa et al. 2014; Csiki et al. 2015). By contrast, the Cretaceous Central Asian ankylosaurs lived in arid to semi-arid habitats that were characterized by active and stabilized dune fields, complemented by episodic fluvial environments with relatively little freshwater supply (Jerzykiewicz and Russell 1991; Dashzeveg et al. 1995; Loope et al. 1998; Jerzykiewicz 2000). Ankylosaurs living under humid, tropical to subtropical climates might have eaten tougher leaves, stems, bark, and seeds that had higher cellulose and lignin content and that had to be ruptured for digestion before swallowing (King 1996). The undergrowth in these humid environments is mainly represented by ferns (e.g. Osmundaceae, Polipodiaceae) and angiosperms (e.g. Araceae, Proteaceae) (Koppelhus 2005; Popa et al. 2014). Processing of these plants would have been aided by a continuous shearing bite, controlled by an efficient musculature, in which the labiolingually compressed, cuspidate upper and lower teeth precisely occluded with each other. On the other hand, Central Asian ankylosaurids, living under more xeric conditions, might have consumed other types of plants (perhaps more succulent forms), the pre-digestive preparation of which did not require such complex chewing. Alternatively, these ankylosaurs might have relied more on hindgut fermentation than on oral processing.

The development of complex tooth morphology, dental occlusion, and a biphasal jaw mechanism during the late Early Cretaceous, and the progressive widening of the muzzle in some lineages during the Late Cretaceous, are craniodental novelties that may at least 
partially account for the evolutionary success of the ankylosaurs. These changes imply that oral food processing became more effective and, at least in some lineages, the amount of processed plant food might have been increased in accordance with generally increasing body size.

\section{Conclusions}

Analysis of craniodental features in ankylosaurs reveals the appearance of numerous functional morphological novelties during the evolution of the group, and mapping these features onto the phylogenetic tree of ankylosaurs (Thompson et al. 2012; Arbour and Currie 2016) inspires the following conclusions:

1) Precise tooth occlusion was absent in the basalmost thyreophorans (Scutellosaurus, Emausaurus). The earliest and basalmost form with precise tooth occlusion (in a puncturecrushing feeding mechanism) is Scelidosaurus (Barrett 2001). In basal ankylosaurs, the muzzle is relatively narrow, premaxillary teeth are present in many forms, and the cingulum is absent or weekly developed on the teeth (but well developed in Kunbarrasaurus Leahey et al. 2015). Tooth-tooth contact, if present (e.g., Gargoyleosaurus), was incidental or local, and a biphasal jaw mechanism was not present.

2) In late Early Cretaceous nodosaurids of North America and Europe, the premaxillary teeth are still present in many forms, the cingulum is more pronounced, the attachment surfaces for the cranial adductors (e.g. pterygoid, coronoid process) are well developed, and muzzle shape becomes more diverse but still relatively narrow. The earliest unambiguous evidence for dental occlusion along the whole tooth row occurs in the Albian Sauropelta that might have been completed by a biphasal jaw mechanism (orthal closure + palinal movement). 
3) Among Late Cretaceous North American ankylosaurs, the muzzle is generally wide and morphologically diverse, premaxillary teeth are absent, and teeth bear a massive cingulum. By contrast, the European forms retain a narrow muzzle with premaxillary teeth. Complex jaw movement with a palinal component appears to have evolved independently in various lineages of North American and European nodosaurids (?Sauropelta, EdmontoniaPanoplosaurus, Hungarosaurus) (teeth of Asian nodosaurids are unknown). This mechanism required some mobility of the predentary-dentary contact to allow long-axis rotation of the mandibular rami.

4) Dental occlusion and a biphasal jaw mechanism was not present in ankylosaurid dinosaurs except for some Late Cretaceous North American forms (Euoplocephalus and Ankylosaurus), where tooth occlusion and palinal movement (at least in Euoplocephalus) appeared independently from the nodosaurids. A progressive widening of the muzzle is seen in Albian to Maastrichtian Asian ankylosaurids, and probably correlates to foraging time and food type, as in herbivorous mammals.

5) Oral processing with dental occlusion and a complex jaw mechanism early evolved multiple times by the late Early Cretaceous in North American (both ankylosaurid and nodosaurid) and European forms, whereas no evidence of such features is seen so far in Asian forms. If this pattern represents a genuine difference between Asian and non-Asian Cretaceous ankylosaurs, it might relate to the different types of vegetation consumed by these low-level feeders in different habitats on different landmasses (i.e. humid, subtropical environments in North America and Europe versus the arid-to semiarid conditions in Asia).

6) Functional tooth-tooth contact involved in a complex jaw mechanism appeared in ankylosaurs no earlier than the late Early Cretaceous. These changes were generated by the diversification of craniodental features, followed by a trend of increasing muzzle width and jaw adductor attachment size. One possible reason for the appearance of these functional 
morphological novelties might be paleofloral change during the Cretaceous, but this cannot be supported at the moment.

\section{Acknowledgements}

We thank Victoria Arbour and Ralph Molnar for their constructive comments that highly improved the MS. The authors thank Juri Miyamae and Daniel L. Brinkman (PMNH, New Haven, Connecticut, USA) for images on the Sauropelta teeth, Joshua Schmerge (UKNHM, Lawrence, USA) for pictures on Silvisaurus, Ken Carpenter (USU EPM, USA) for sending the cast of Peloroplites tooth, Jim Kirkland (UGS, Salt Lake City, Utah, USA) for pictures on Gastonia. We are grateful to Tibor Pecsics (Eötvös University, Budapest, Hungary) for the illustrations on ankylosaur skulls.

We thank Magdalena Borsuk-Białynicka (PAS, Warsaw, Poland), Tatiana Tumanova (PIN, Moscow, Russia), Mark Norell (AMNH, New York, USA), Michael Brett-Surman (USNM, Washington DC, USA), Carl Mehling (AMNH, New York, USA), Kieran Shepeard, Alan McDonald, and Margaret Currie (CMN, Ottawa, Canada), Kevin Seymour and David Evans ( $\mathrm{ROM}_{2}$ Toronto, Canada), Jim Gardner, Don Henderson, Brandon Strilisky and Becky Sanchez (TMP, Drumheller, Canada), Mike Caldwell and Victoria Arbour (University of Edmonton, Edmonton, Canada), Luis Alcala and Eduardo Espínez (Dinopolis, Teruel, Spain), Suzanne Jiquel and Laurent Marivaux (UM2, Montpellier, France) for access to specimens. We are grateful to Gábor Botfalvai (MTA-ELTE Lendület Research Group, Budapest, Hungary), Ádám Kocsis (MTA-MTM-ELTE Paleontological Research Group) and Bob Sullivan (Harrisburg, PA, USA) for useful consultations, Péter Gulyás, Réka Kalmár, Zsófia Hajdu and Dóra Csengődi (MTA-ELTE Lendület Research Group) for preparation of the Törölt: group specimens, and Krisztina Buczkó (MTM, Budapest, Hungary) for help with the SEM. 


\section{References}

Arbour VM, Burns ME, Sissons RL 2009. A redescription of the ankylosaurid dinosaur

Dyoplosaurus acutosquameus Parks, 1924 (Ornithischia: Ankylosauria) and a revision of the genus. J Vert Pal. 29:1117-1135.

Arbour VM, Burns ME, Sullivan RM, Lucas SG, Cantrell AK, Fry J, Suazo TL. 2014b. A new ankylosaurid dinosaur from the Upper Cretaceous (Kirtlandian) of New Mexico, with implications for ankylosaurid diversity in the Upper Cretaceous of western North America. PLOS ONE. 9(9): e108804. doi:10.1371/journal.pone.0108804.

Arbour VM, Currie PJ. 2013. Euoplocephalus tutus and the Diversity of Ankylosaurid

Dinosaurs in the Late Cretaceous of Alberta, Canada, and Montana, USA. PLoS ONE

8(5): e62421. doi:10.1371/journal.pone.0062421.

Arbour VM, Currie PJ. 2016. Systematics, phylogeny and palaeobiogeography of the ankylosaurid dinosaurs, J Sys Palaeont. 14:385-444. doi:

10.1080/14772019.2015.1059985.

Arbour VM, Currie PJ, Badamgarav D. 2014a. The ankylosaurid dinosaurs of the Upper

Formázott: francia (franciaországi) Cretaceous Baruungoyot and Nemegt formations of Mongolia. Zool J Linn Soc.

$172: 631-652$.

Arbour VM, Zanno LE, Gates T. 2016. Ankylosaurian dinosaur palaeoenvironmental

associations were influenced by extirpation, sea-level fluctuation, and geodispersal.

Palaeogeogr, Palaeoclimat, Palaeoecol. doi:10.1016/j.palaeo.2016.02.033

Formázott: francia (franciaországi)

Formázott: angol (egyesült királysági)

Formázott: angol (egyesült királysági)

Astibia H, Murelaga X, Pereda Suberbiola X, Elorza JJ, Gómez-Aldalay JJ. 1999.Taphonomy and palaeoecology of the Upper Cretaceous continental vertebrate-bearing beds of the Laño quarry (Iberian Peninsula). Est Mus Cienc Nat de Alava. 14 (Núm. Espec. 1): 43104. 
Averianov AO. 2002. An ankylosaurid (Ornithischia: Ankylosauria)from the Upper

Cretaceous Bissekty Formation of Uzbekistan. Bull l'Inst R Sci Nat de Belg, Sci de la T. $72: 97-110$.

Bakker RT. 1978. Dinosaur feeding behavior and the origin of flowering plants. Nature 274: 661-663.

Barrett PM. 2001. Tooth wear and possible jaw action of Scelidosaurus harrisonii Owen and a review of feeding mechanisms in other thyreophoran dinosaurs. In: Carpenter K, Kirkland JI, editors. The Armored Dinosaurs. Indiana University Press, Bloomington. p. $25-52$.

Barrett PM, You H, Upchurch P, Burton AC. 1998. A new ankylosaurian dinosaur (Ornithischia: Ankylosauria) from the Upper Cretaceous of Shanxi Province, People's Republic of China. J Vert Paleont 18(2):376-384.

Baumel JJ. 1993. Handbook of avian anatomy: nomina anatomica avium. Publications of the Nuttall Ornithological Club (USA) no. 23. 2nd ed. Boston (MA).

Blows WT. 1996. A new species of Polacanthus (Ornithischia: Ankylosauria) from the Lower Cretaceous of Sussex, England. Geol Mag. 133(6):671-682.

Bodor E, Baranyi V. 2012. Palynomorphs of the Normapolles group and related plant mesofossils from the Iharkút vertebrate site, Bakony Mountains (Hungary). Cent Eur Geol. 55(3):259-29.

Bowman RI. 1961. Morphological differentiation and adaptation in the galápagos finches. Uni California Publ Zool. 58: 1-302.

Brown SAE, Scott AC, Glasspool IJ, Collinson ME. 2012. Cretaceous Wildfires and Their Impact on the Earth System. Cret Res. 36:162-90.

Burns ME. 2008. Taxonomic utility of ankylosaur (Dinosauria, Ornithischia) osteoderms:

Glyptodontopelta mimus Ford, 2000: a test case. J Vert Pal. 28(4): 1102-1109. 
Burns ME, Currie PJ. 2012. Quantitative analyses of cranial characters in Panoplosaurus and Edmontonia (Ankylosauria: Nodosauridae) and their taxonomic implications for the clade. In: Journal of Vertebrate Paleontology Program and Abstracts. 72nd Annual Meeting of the Society of Vertebrate Paleontology, Raleigh, North Carolina. Burns ME, Sullivan RM. 2011. A new ankylosaurid from the Upper Cretaceous Kirtland Formation, San Juan Basin, with comments on the diversity of ankylosaurids in New Mexico. New Mexico Mus Nat His Sci Bul. 53:169-178.

Busbey AB. 1989. Form and function of the feeding apparatus of Alligator mississippiensis. J Morph. 202(1):99-127.

Carpenter K. 2001. Phylogenetic analysis of the Ankylosauria. In: Carpenter K, Kirkland JI, editors. The Armored Dinosaurs. Indiana University Press, Bloomington. p. 455-483. Carpenter K. 2004. Redescription of Ankylosaurus magniventris Brown 1908

(Ankylosauridae) from the Upper Cretaceous of the Western Interior of North America. Can J Earth Sci. 41:961-986.

Carpenter K. 2012. Ankylosaurs. In Brett-Surman MK, Holtz TR, Farlow JO editors. The Complete Dinosaur. 2nd edition. Indiana University Press, Bloomington; p. 505-252. Carpenter K, Bartlett J, Bird J, Barrick R. 2008. Ankylosaurs from the Price River Quarries, Cedar Mountain Formation (Lower Cretaceous), east-central Utah. J Vert Pal. 28:10891101.

Carpenter K, Dilkes D, Weishampel DB. 1995. The dinosaurs of the Niobrara Chalk Formation (Upper Cretaceous, Kansas). J Vert Pal. 15:275-297.

Carpenter K, Everhart MJ. 2007. Skull of the ankylosaur Niobrarasaurus coleii (Ankylosauria: Nodosauridae) from the Smoky Hill Chalk (Coniacian) of western Kansas. Trans Kansas Acad Sci 110(1/2):1-9. 
Carpenter K, Hayashi S, Kobayashi Y, Maryanska T, Barsbold R, Sato K, Obata I. 2011.

Saichania chulsanensis (Ornithischia, Ankylosauridae) from the Upper Cretaceous of Mongolia. Palaeont Abteil A. 293:1-61.

Carpenter K, Kirkland JI. 1998. Review of Lower and Middle Cretaceous ankylosaurs from North America. In: Lucas, S. G., Kirkland, J. I., and Estep, J. W. (eds.). Lower and Middle Cretaceous Ecosystems. New Mexico Mus. Nat. Hist. Sci. Bull. 14: 249-270.

Carpenter K, Kirkland JI, Burge DL, Bird J. 1999. Ankylosaurs (Dinosauria: Ornithischia) of the Cedar Mountain Formation, Utah and their stratigraphic distribution. In: Gillette, D. D. (ed.). Vertebrate Paleontology in Utah. Utah Geol. Surv. Misc. Publ. 99-1: 243-251. Carpenter K, Kirkland JI, Burge DL, Bird J. 2001. Disarticulated skull of a new primitive ankylosaurid from the Lower Cretaceous of eastern Utah. In: Carpenter K, Kirkland JI, editors. The Armored Dinosaurs. Indiana University Press, Bloomington. p.211-238.

Chen R, Zheng W, Azuma Y, Shibata M, Lou T, Jin Q, Jin X. 2013. A new nodosaurid ankylosaur from the Chaochuan Formation of Dongyang, Zhejiang Province, China. Acta Geol Sin (English Edition). 87:801-840.

Clutton-Brock TH, Harvey PH. 1983. The functional significance of variation in body size among mammals. Advances in the study of mammalian behaviour (Special Publication of the American Society for Mammalogy 7). Shippenburg State College, Shippenburg, p. $632-663$.

Colbert EH. 1981. A primitive ornithischian dinosaur from the Kayenta Formation of Arizona. Bull. Mus. N. Arizona. 53: 1-61.

Coombs WP Jr. 1971. The Ankylosauria [Ph.D. dissertation]. Columbia University, New York. 
Coombs WP Jr. 1990. Teeth and taxonomy in ankylosaurs. In: Carpenter K, Currie PJ editors.

Dinosaur Systematics: Approaches and Perspectives. Cambridge: Cambridge

University Press. p. 269-279.

Coombs WP Jr. 1995. A new nodosaurid ankylosaur (Dinosauria:Ornithischia) from the Lower Cretaceous of Texas. J Vert Paleont. 15:298-312.

Coombs WP, Deméré TA. 1996. A Late Cretaceous nodosaurid ankylosaur (Dinosauria:

Ornithischia) from marine sediments of coastal California. J Paleont. 70(02):311-326.

Crompton A, Hiiemae K. 1970. Molar occlusion and mandibular movements during

occlusion, Didelphis marsupialis L. Zool J Linn Soc. 49:21-47.

Csiki-Sava Z, Buffetaut E, Ösi A, Pereda-Suberbiola X, Brusatte SL. 2015. Island life in the

Cretaceous-faunal composition, biogeography, evolution, and extinction of land-living vertebrates on the Late Cretaceous European archipelago. ZooKeys. 469(1).

Csiki-Sava Z, Vremir M, Vasile Ş, Brusatte SL, Dyke G, Naish D, Norell M, Totoianu R.

2016. The East Side Story-The Transylvanian latest Cretaceous continental vertebrate record and its implications for understanding Cretaceous-Paleogene boundary events. Cret Res. 57:662-698.

Dashzeveg D, Novacek MJ, Norell MA, Clark JM, Chiappe LM, Davidson A, McKenna MC, Dingus L, Swisher C, Altangerel P. 1995. Extraordinary preservation in a new vertebrate assemblage from the Late Cretaceous of Mongolia. Nature. 374(6521):446449.

Dodson P. 1971. Sedimentology and taphonomy of the Oldman Formation (Campanian), Dinosaur Provincial Park, Alberta (Canada). Palaeogeogr.Palaeoclimatol. Palaeoecol. 10:21-74.

Dompierre H, Churcher CS. 1996. Premaxillary shape as an indicator of the diet of seven extinct late Cenozoic New World camels. J Vert Paleont. 16(1):141-148. 
Dong Z. 1993. An ankylosaur (ornithischian dinosaur) from the Middle Jurassic of the Junggar Basin, China. Vert PalAsiatica. 31:257-266.

Dong ZM. 2002. A new armored dinosaur (Ankylosauria) from Beipiao Basin, Liaoning Province, northeastern China.Vert PalAsiatica. 10:276-285.

Eaton TH Jr. 1960. A new armored dinosaur from the Cretaceous of Kansas. The University of Kansas Palaeontological Contributions: Vertebrata. 8:1-24.

Eberth DA. 2005. The geology. In Dinosaur Provincial Park: a spectacular ancient ecosystem revealed. Currie PJ, Koppelhus EB, editors. Bloomington: Indiana University Press. p. $54-82$.

Eberth DA. 2015. Origins of dinosaur bonebeds in the Cretaceous of Alberta, Canada 1. Can J Earth Sci. 52(8):655-681.

Eberth DA, Braman DR, Tokaryk TT. 1990. Stratigraphy, sedimentology and vertebrate paleontology of the Judith River Formation (Campanian) near Muddy Lake, westcentral Saskatchewan. Bull. Can.Pet. Geol. 38:387-406.

Eberth DA, Hamblin AP. 1993. Tectonic, stratigraphic, and sedimentologic significance of a regional discontinuity in the upper Judith River Group (Belly River wedge) of southern Alberta, Saskatchewan, and northern Montana. Can J Earth Sci. 30(1):174-200.

Endo H, Aoki R, Taru H, Rimura J, Sasaki M, Yamamoto M, Arishima K, Hayasi Y. 2002. Comparative functional morphology of the masticatory apparatus in the long-snouted crocodiles. Anat Hist Embryol. 31:206-213.

Erickson GM. 1996. Incremental lines of von Ebner in dinosaurs and the assessment of tooth replacement rates using growth line counts. Proc Nat Acad Sci. 93(25):14623-14627.

Ford TL. 2000. A review of ankylosaur osteoderms from New Mexico and a preliminary review of ankylosaur armor. New Mexico Mus Nat Hist Sci Bull. 17:157-176. 
Ford TL, Kirkland JI. 2001. Carlsbad ankylosaur (Ornithischia,Ankylosauria): An

ankylosaurid and not a nodosaurid. In: Carpenter K, Kirkland JI, editors. The Armored Dinosaurs. Indiana University Press, Bloomington. p. 239-260.

Fricke HC, Foreman BZ, Sewall JO. 2010. Integrated climate model-oxygen isotope evidence for a North American monsoon during the Late Cretaceous. Earth Planet Sci Letters. 289(1):11-21.

Galton PM. 1973. The cheeks of ornithischian dinosaurs. Lethaia 667-89.

Galton PM. 1980a. Priodontognathus phillipsii (Seeley), an ankylosaurian dinosaur from the Upper Jurassic (or possibly Lower Cretaceous) of England. N Jb Geol Paläontol Mh 1980: 477-489.

Galton PM. 1980b. Armored dinosaurs (Ornithischia: Ankylosauria) from the Middle and Upper Jurassic of England. Géobios. 13(6):825-837.

Galton PM. 1983. Sarcolestes leedsi Lydekker, an ankylosaurian dinosaur from the Middle Jurassic of England. N Jb Geol Paläontol Mh. 1983:141-155.

Galton PM. 1986. Herbivorous adaptations of Late Triassic and Early Jurassic dinosaurs. In: Padian K, editor. The Beginning of the Age of Dinosaurs. Cambridge: Cambridge University Press. p. 203-221.

Garcia G, Pereda-Suberbiola X. 2003. A new species of Struthiosaurus (Dinosauria:

Ankylosauria) from the Upper Cretaceous of Villeveyrac (southern France). J Vert Paleont. 23(1):156-165.

Gasparini Z, Pereda-Suberbiola X, Molnar RE. 1996. New data on the ankylosaurian dinosaur from the Late Cretaceous of the Antarctic Peninsula. Mem Queensland Mus. 39:583594. 
Gilmore CW. 1914. Osteology of the armored Dinosauria in the United States National

Museum, with special reference to the genus Stegosaurus. United States Nat Mus Bull. 89:1-136.

Godefroit P, Pereda-Suberbiola X, Li H, Dong Z. 1999. A new species of the ankylosaurid dinosaur Pinacosaurus from the Late Cretaceous of Inner Mongolia (P. R. China). Bull Inst Roy Sci Nat Belg Sci Terre. 69:17-36.

Gordon IJ, Illius AW. 1988. Incisor arcade structure and it selection in ruminants. Func Ecology. 2:15-22.

Greaves WS. 1973. The inference of jaw motion from tooth wearfacets. J Paleontol. 47:10001001.

Grine F. 1986. Dental evidence for dietary differences in Australopithecus and Paranthropus: A quantitative analysis ofpermanent molar microwear. J Hum Evol. 15:783-822.

Haas G. 1969. On the jaw muscles of ankylosaurs. Amer Mus Nov. 2399:1-11.

Hammer Ø, Harper DAT, Ryan PD. 2001. PAST: Paleontological statistics software package for education and data analysis. Palaeontol Electronica. 4(1): 9pp.

Han F, Zheng W, Hu D, Xu X, Barrett PM. 2014. A new basal ankylosaurid (Dinosauria:

Ornithichia) from the Lower Cretaceous Jiufotang Formation of Liaoning Province, China. PLOS ONE. 9:e104551.

Haubold H. 1990. Ein neuer Dinosaurier (Ornithischia, Thyreophora) aus dem Unteren Jura des nordlichen Mitteleuropa. Rev Paleobiol. 9:149-177. [In German.]

Hill RV, D'Emic MD, Bever GS, Norell MA. 2015. A complex hyobranchial apparatus in a Cretaceous dinosaur and the antiquity of avian paraglossalia. Zool J Linn Soc. 175(4):892-909. 
Hill RV, Witmer LW, Norell MA. 2003. A new specimen of Pinacosaurus grangeri

(Dinosauria: Ornithischia) from the Late Cretaceous of Mongolia: ontogeny and phylogeny of ankylosaurs. Am MusNov. 3395:1-29.

Holliday CM. 2009. New perspectives on dinosaur jaw muscle anatomy. Anat Rec. 292:1246-1265.

Holliday CM, Witmer LM. 2007. Archosaur adductor chamber evolution: integration of musculoskeletal and topological criteria in jaw muscle homology. J Morphol. 268(6):457-484.

Hwang SH. 2005. Phylogenetic patterns of enamel microstructure in dinosaur teeth. J Morphol. 266:208-240.

Illius AW, Gordon IJ. 1987. The allometry of food intake in grazing ruminants. J Anim Ecol. $56: 989-999$

Iordansky NN. 1964. The jaw muscles of the crocodiles and some relating structures of the crocodilian skull. Anatom Anz.115:256-280.

Janis CM, Ehrhardt D. 1988. Correlation of relative muzzle width and relative incisor width with dietary preference in ungulates. Zool J Linn Soc. 92(3):267-284.

Jarman PJ. 1974. The social organization of antelope in relation to their ecology. Behaviour 48:215-267.

Jarzen DM. 1982. Angiosperm pollen from the Ravenscrag formation (Paleocene) southern Saskatchewan, Canada. Pollen Spores, 24(1):119-155.

Jerzykiewicz T. 2000. Lithostratigraphy and sedimentary settings of the Cretaceous dinosaur beds of Mongolia.In: Benton MJ, Shishkin MA, Unwin DM, Kurochkin EN, editors. The Age of Dinosaurs in Russia and Mongolia. Cambridge: Cambridge University Press. p. 279-296. 
Jerzykiewicz T, Russell DA. 1991. Late Mesozoic stratigraphy and vertebrates of the Gobi Basin, Cret Res. 12(4):345-377.

Ji Q, Wu X, Cheng Y, Wang X. 2015. Discovery of fish hunting ankylosaurs (Dinosauria:

Ornithischia) from the Cretaceous of China pp. Abstracts of International Symposium on Asian Dinosaurs in Fukui 2014, Fukui Prefectural Dinosaur Museum: Fukui. 1 1-2 of supplement.

Kilbourn, B, Carpenter K. 2005. Redescription of Gargoyleosaurus parkpinorum, a polacanthid ankylosaur from the Upper Jurassic of Albany County, Wyoming. - N Jb Geol Palaeont Abhl. 237:111-160.

King GM. 1996. Reptiles and herbivory. London: Chapman and Hall.

Kirkland JI. 1998. A polacanthine ankylosaur (Ornithischia:Dinosauria) from the Early Cretaceous (Barremian) of eastern Utah. New Mexico Mus Nat Hist Sci Bull. 14:271281.

Kirkland JI, Alcalá L, Loewen, MA, Espílez E, Mampel L, Wiersma JP. 2013. The basal nodosaurid ankylosaur Europelta carbonensis n. gen., n. sp. from the Lower Cretaceous (Lower Albian) Escucha Formation of Northeastern Spain. PLOS ONE. 8(12):e80405.

Kirkland JI, Carpenter K. 1994. North America's first pre-Cretaceous ankylosaur (Dinosauria) from the Upper Jurassic Morrison Formation of western Colorado. Brigham Young Uni Geol Stud. 40:25-42.

Kirkland JI, Carpenter K, Hunt AP, Scheetz RD. 1998. Ankylosaur (Dinosauria) specimens from the Upper Jurassic Morrison Formation. In: Carpenter, K., Chure, D. J., and Kirkland, J. I. (eds.). The Upper Jurassic Morrison Formation: An Interdisciplinary Study. Part 2. Modern Geol. 23:145-177.
Formázott: német (németországi) Formázott: angol (egyesült királysági)

Formázott: angol (egyesült királysági)

Formázott: angol (egyesült királysági) 
Koppelhus EB. 2005. Paleobotany. In Currie PJ, Koppelhus EB editors. Dinosaur Provincial Park: a spectacular ancient ecosystem revealed. Indiana University Press, Bloomington, p. $131-138$.

Kurzanov SM, Tumanova TA. 1978. The structure of the endocranium in some Mongolian ankylosaurs. Paleontol J. 1978(3):369-374.

Lambe LM. 1919. Description of a new genus and species (Panoplosaurus mirus) of armored dinosaur from the Belly River Beds of Alberta. Trans Roy Soc Can. 3(13): 39-50.

Leahey LG, Molnar RE, Carpenter K, Witmer LM, Salisbury SW. 2015. Cranial osteology of the ankylosaurian dinosaur formerly known as Minmi sp.(Ornithischia: Thyreophora) from the Lower Cretaceous Allaru Mudstone of Richmond, Queensland, Australia. PeerJ. 3:e1475.

Lee Y-N. 1996. A new nodosaurid ankylosaur (Dinosauria:Ornithischia) from the Paw Paw Formation (late Albian) of Texas. J Vert Paleont. 16:232-245.

Loope DB, Dingus L, Swisher CC, Minjin C. 1998. Life and death in a Late Cretaceous dune field, Nemegt basin, Mongolia. Geology. 26(1):27-30.

Lull RS. 1921. The Cretaceous armored dinosaur, Nodosaurus textilis Marsh. Am J Sci. Ser. 5 $1(2): 97-126$

Lull RS, Clark WB, Berry EW. 1911. Systematic paleontology of the Lower Cretaceous deposits of Maryland: Vertebrata. In: Maryland Geological Survey, Lower Cretaceous Volume. p. 183-211.

Lü J, Jin X, Sheng Y, Li Y, Wang G, Azuma Y. 2007. New nodosaurid dinosaur from the Late Cretaceous of Lishui, Zhejiang Province, China. Acta Geol Sinica. 81(3):344-350. Maleev EA. 1952. A new ankylosaur from the Upper Cretaceous of Mongolia. Doklady Akademii Nauk SSSR 87(2):273-276. [In Russian] 
Mallon JC, Anderson JS. 2013. Skull ecomorphology of megaherbivorous dinosaurs from the Dinosaur Park Formation (upper Campanian) of Alberta, Canada. PLoS One. 8(7):e67182.

Mallon JC, Anderson JS. 2014a. The functional and palaeoecological implications of tooth morphology and wear for the megaherbivorous dinosaurs from the Dinosaur Park Formation (upper Campanian) of Alberta, Canada. PloS one. 9(6):e98605.

Mallon JC, Anderson JS. 2014b Implications of beak morphology for the evolutionary paleoecology of the megaherbivorous dinosaurs from the Dinosaur Park Formation (upper Campanian) of Alberta, Canada. Palaeogeogr Palaeoclimatol Palaeoecol. 394: $29-41$.

Mallon JC, Anderson JS. 2015. Jaw mechanics and the evolutionary palaeoecology of the megaherbivorous dinosaurs from the Dinosaur Park Formation (upper Campanian) of Alberta, Canada. J Vert Paleontol. 35:e904323.

Mallon JC, Evans DC, Ryan MJ, Anderson JS. 2013. Feeding height stratification among the herbivorous dinosaurs from the Dinosaur Park Formation (upper Campanian) of Alberta, Canada. BMC Ecology. 13:14. doi:10.1186/1472-6785-13-14

Marsh OC. 1888. Notice of a new genus of Sauropoda and other new dinosaurs from the Potomac Formation. Am J Sci. ser. 3, 35:89-94.

Marsh OC. 1889. Notice of gigantic horned Dinosauria from the Cretaceous. Am J Sci. $38: 173-175$

Maryanska T. 1977. Ankylosauridae (Dinosauria) from Mongolia. Palaeontol Polonica. 37: $85-151$.

Maynard-Smith SJ, Savage RJG. 1959. The mechanics of mammalian jaws. School Sci Rev. 40:289-301. 
Miles CA, Miles CJ. 2009. Skull of Minotaurasaurus ramachandrani, a new Cretaceous ankylosaur from the GobiDesert. Current Sci. 96:65-70.

Mills JRE. 1967. A comparison of lateral jaw movements in some mammals from wear facets on the teeth. Arch Oral Biol. 12:645-661.

Molnar RE. 1980. An ankylosaur (Ornithischia: Reptilia) from the Lower Cretaceous of southern Queensland. Mem Queensland Mus. 20:77-87.

Molnar RE. 1996. Preliminary report on a new ankylosaur from the Early Cretaceous of Queensland, Australia. Mem Queensland Mus. 39:653-668.

Molnar RE, Clifford HT. 2000. Gut contents of a small ankylosaur. J Vert Pal 20:194-196.

Molnar RE, Clifford HT. 2001. An ankylosaurian cololite from the Lower Cretaceous of

Queensland, Australia. In: Carpenter K, Kirkland JI, editors. The Armored Dinosaurs. Indiana University Press, Bloomington. Pp. 399-412.

Moodie RL. 1910. An armored dinosaur from the Cretaceous of Wyoming. Kansas Uni Sci Bull. 5:257-273.

Mueller-Töwe IJ. 2006. Feeding options in Steneosaurus bollensis (Mesoeucrocodylia. Thalattosuchia). Hantkeniana Spec. 5:46-48.

Nabavizadeh A, Weishampel BD. Forthcoming 2016. The predentary bone and its significance in the evolution of feeding mechanisms in ornithischian dinosaurs. Anat Rec.

Noad JJ. 1993. An analysis of changes in fluvial architecture through the upper Oldman Member, Judith River Formation of the Upper Cretaceous, southern Alberta, Canada [master's thesis]: Birkbeck College, University of London.

Nopcsa F. 1928. Palaeontological notes on reptiles. Geol Hungarica, Ser Palaeontol. 1:1-84. Nopcsa BF. 1929. Dinosaurierreste aus Siebenbürgen V. [Dinosaur remains from

Siebenbürgen V]. Geol Hungarica, Ser Palaeontol. 4:1-72 
Norman DB, Faiers T. 1996. On the first partial skull of an ankylosaurian dinosaur from the Lower Cretaceous of the Isle of Wight, southern England. Geol Mag. 133:299-310.

Ostrom J. 1970. Stratigraphy and paleontology of the Cloverly Formation (Lower Cretaceous) of the Bighorn Basin Area, Wyoming and Montana. Bull Peabody Mus Nat Hist. 35.

Owen R. 1861. Monograph of the Fossil Reptilia of the Liassic formations. Part 1. A monograph of a fossil dinosaur (Scelidosaurus harrisonii Owen) of the Lower Lias. Palaeontogr Soc Monogr. 1:1-14.

Owen-Smith RN. 1979. Assessing the foraging efficiency of a large herbivore, the kudu. South African J Wildlife Res. 9:102-110.

Owen-Smith RN. 1982. Factors influencing the consumption of plant products by large herbivores. In: Huntley BJ, Walker BH editors. Ecology of tropical savannas. Springer Berlin Heidelberg p. 359-404.

Owen-Smith RN. 1985. Niche separation among African ungulates. Species and Speciation. Transvaal Mus Monogr 4: 167-171.

Owen-Smith RN. 1988. Megaherbivores: The Influence of Very Large Body Size on Ecology. Cambridge University Press, Cambridge, England.

Ösi A. 2005. Hungarosaurus tormai, a new ankylosaur (Dinosauria) from the Upper Cretaceous of Hungary. J Vert Paleontol. 25:370-383.

Ösi A. 2014. The evolution of jaw mechanism and dental function in heterodont crocodyliforms. Histor Biol. 26:279-414.

Ösi A. 2015. The European ankylosaur record: a review. Hantkeniana, 10: 89-106. Ősi A, Barrett P, Földes T, Tokai R. 2014a. Wear Pattern, Dental Function, and Jaw Mechanism in the Late Cretaceous Ankylosaur Hungarosaurus. Anat Rec. 297:1165Formázott: angol (egyesült királysági) Formázott: angol (egyesült királysági) Formázott: Betűtípus: Nem Dőlt Formázott: angol (egyesült királysági) Formázott: Behúzás: Bal: $0 \mathrm{~cm}$, Függő: $1,27 \mathrm{~cm}$ 1180. 
Ösi A, Prondvai E, Csiki-Sava Z. 2014b. New ankylosaurian material from the Upper Cretaceous of Transylvania. Annal Paléontol. 100:257-271.

Ösi A, Weishampel DB. 2009. Jaw mechanism and dental function in the Late Cretaceous basal eusuchian Iharkutosuchus. J Morphol. 270(8):903-920.

Pang Q, Cheng Z. 1998. A new ankylosaur of Late Cretaceous from Tianzhen, Shanxi. Prog Nat Sci. 8(3):326-334

Parks WA. 1924. Dyoplosaurus acutosquameus, a new genus and species of armored dinosaur, and notes on a skeleton of Prosaurolophus maximus. Uni Toronto Stud Geol Ser. 18:1-35.

Parsons WL, Parsons KM. 2009. A new ankylosaur (Dinosauria: Ankylosauria) from the Lower Cretaceous Cloverly Formation of central Montana. Canadian J Earth Sci. $46: 721-738$

Penkalski P. 2014. A new ankylosaurid from the late Cretaceous Two Medicine Formation of Montana, USA. Acta Palaeontol Polonica. 59:617-634.

Penkalski P, Blows WT. 2013. Scolosaurus cutleri (Ornithischia: Ankylosauria) from the Upper Cretaceous Dinosaur Park Formation of Alberta, Canada. Canadian J Earth Sci. 50(2):171-182.

Pereda-Suberbiola X. 1994. Polacanthus (Ornithischia, Ankylosauria), a transatlantic armoured dinosaur from the Early Cretaceous of Europe and North America. Palaeontograph Abl. A 232:133-159.

Pereda-Suberbiola X, Astibia H, Buffetaut E. 1995. New remains of the armoured dinosaur Struthiosaurus from the Late Cretaceous of the Iberian Peninsula (Lano locality, Basque-Cantabric Basin). Bull Soc Géol France. 166:105-109.

Pereda-Suberbiola X, Barrett PM. 1999: A systematic review of ankylosaurian dinosaur remains from the Albian-Cenomanian of England. - Spec Pap Palaeontol. 60:177-208. 
Pereda-Suberbiola X, Galton PM. 2001. Reappraisal of the nodosaurid ankylosaur

Struthiosaurus austriacus Bunzel. In: Carpenter K, Kirkland JI, editors. The Armored Dinosaurs. Indiana University Press, Bloomington. Pp. 173-210.

Peters RH. 1983. The Ecological Implications of Body Size. Cambridge University Press, Cambridge, 329 pp.

Pol D. 2003. New remains of Sphagesaurus huenei (Crocodylomorpha:Mesoeucrocodylia) from the Late Cretaceous of Brazil. J Vertebr Paleontol. 23:817-831.

Popa ME, Kvacek J, Vasile S, Csiki-Sava Z. 2014. Maastrichtian monocotyledons of the Rusca Montan_a and Hat, eg basins, South Carpathians, Romania. Review of Palaeobotany and Palynology, 210, 89-101.

Popowics TT, Fortelius M. 1997. On the cutting edge: Tooth blade sharpness in herbivorous and faunivorous mammals. Ann. Zool.Fennici 34: 73-88.

Raza A, Hill KC, Korsch RJ. 2009. Mid-Cretaceous uplift and denudation of the Bowen and Surat Basins, eastern Australia: relationship to Tasman Sea rifting from apatite fissiontrack and vitrinite-reflectance data. Austr J Earth Sci 56: 501-531.

Rensberger JM. 1973. An occlusal model for mastication and dental wear in herbivorous Törölt: mammals. J Paleontol 47:515-528.

Russell LS. 1940. Edmontonia rugosidens (Gilmore), an armoured dinosaur from the Belly River series of Alberta. University of Toronto Studies, Geological Series, 43, 3-28, pls $1-8$

Rybczynski N, Vickaryous MK. 2001. Evidence of complex jaw movement in the Late

Cretaceous ankylosaurid Euoplocephalus tutus (Dinosauria: Thyreophora In: Carpenter

K, Kirkland JI, editors. The Armored Dinosaurs. Indiana University Press,

Bloomington. Pp. 299-317. 
Salgado L, Gasparini Z. 2006. Reappraisal of an ankylosaurian dinosaur from the Upper Cretaceous of James Ross Island (Antarctica). Geodiversitas. 28:119-135.

Sander PM, Gee CT, Hummel J, Clauss M. 2010. Mesozoic plants and dinosaur herbivory. In: Gee CT editor: Plants in Mesozoic Time: Morphological Innovations, Phylogeny, Ecosystems. p. 331-359.

Schwenk K. 2000. Feeding in lepidosaurs. In: Schwenk K, editor. Feeding, form, function, and evolution in tetrapod vertebrates. New York: Academic Press. p. 175-291.

Seeley HG. 1875. On the maxillary bone of a new dinosaur (Priodontognathus phillipsii), contained in the Woodwardian Museum of the University of Cambridge. Q J Geol Soc London. 31:439-443.

Seeley HG. 1879. On the Dinosauria of the Cambridge Greensand. Q J Geol Soc London $35: 591-635$

Sereno PC, Dong Z. 1992. The skull of the basal stegosaur Huayangosaurus taibaii and a cladistic analysis of Stegosauria. J Vert Paleontol. 12:318-343.

Shipley LA. 1999. Grazers and browsers: how digestive morphology affects diet selection. In: Launchbaugh KL, Sanders KD, Mosley JC, editors. Grazing Behaviour of Livestock and Wildlife. Idaho Forest, Wildlife and Range Expeditions Station Bulletin, University of Idaho. p. 20-27.

Smith JB, Dodson P. 2003. A proposal for a standard terminology of anatomical notation and orientation in fossil vertebrate dentitions. J Vert Paleontol. 23:1-12.

Smith KK. 1993. The form of the feeding apparatus in terrestrial vertebrates: Studies of adaptation and constraint. In: Hanken J, Hall BK, editors. The Skull. Chicago: University of Chicago Press. pp 150-196.

Solounias N, Teaford M, Walker A. 1988. Interpreting the diet of extinct ruminants: the case of a non-browsing giraffid. Paleobiol. 14:287-300. 
Stanford R, Weishampel DB, Deleon VB. 2011. The first hatchling dinosaur reported from the eastern United States: Propanoplosaurus marylandicus (Dinosauria: Ankylosauria) from the Early Cretaceous of Maryland, U.S.A. J Paleontol. 85:916-924.

Sternberg CM. 1928. A new armored dinosaur from the Edmonton Formation of Alberta. Trans R Soc Canada. ser 3 22:93-106.

Sternberg CM. 1929. A toothless armoured dinosaur from the Upper Cretaceous of Alberta. Canada Department of Mines Geol Surv Bull 54:28-33.

Sullivan RM. 1999. Nodocephalosaurus kirtlandensis, gen. et sp nov., a new ankylosaurid dinosaur (Ornithischia: Ankylosauria) from the Upper Cretaceous Kirtland Formation (Upper Campanian), San Juan Basin, New Mexico. J Vert Paleontol.19:126-139.

Tennant JP, MacLeod N. 2014. Snout shape in extant ruminants. PLOS ONE, 9(11).

Therrien F. 2005. Palaeoenvironments of the latest Cretaceous (Maastrichtian) dinosaurs of Romania: insights from fluvial deposits and paleosols of the Transylvanian and Haţeg basins. Palaeogeograph Palaeoclim Palaeoecol. 218:15-56. doi:

10.1016/j.palaeo.2004.12.005

Thompson RS, Parish JC, Maidment SCR, Barrett PM. 2012. Phylogeny of the ankylosaurian dinosaurs (Ornithischia: Thyreophora). J Sys Palaeont.10:301-312.

Tumanova TA. 1977. New data on the ankylosaur Tarchia gigantea. Paleontolog

Zh 1977(4):92-100. [In Russian]

Tumanova TA. 1983. The first ankylosaurs from the Lower Cretaceous of Mongolia. In

Tatarinov LP, Barsbold R, Vorobyeva E, Luvsandanzan B, Trofimov BA, Yu. A.

Reshetov, Shishkin MA. editors. Iskopayemyye reptilii mongolii [Fossil Reptiles of

Mongolia]. Trudy Sovmestnaya Sovetsko-Mongol'skaya Paleontologicheskaya

Ekspeditsiya 24:110-118. [In Russian] 
Tumanova TA. 1987. The armored dinosaurs of Mongolia. Trudy Sovmestnaya Sovetsko-

Mongol'skaya Paleontologicheskaya Ekspeditsiya 32:1-80. [In Russian]

Tumanova TA. 1993. A new armored dinosaur from southeastern Gobi. Paleontolog Zh.

27:92-98. [In Russian.]

Ungar PS. 1995. A semiautomated image analysis procedurefor the quantification of dental microwear II. Scanning. 17:57-59.

Ungar PS. 1996. Dental microwear of European Miocene catar-rhines: Evidence for diets and tooth use. J Hum Evol 31:355-366.

Van Itterbeeck J, Săsăran E, Codrea V, Săsăran L, Bultynck P. 2004. Sedimentology of the Upper Cretaceous mammal- and dinosaur-bearing sites along the Râul Mare and Bărbat rivers, Haţeg Basin. Cret Res. 25:517-530. doi: 10.1016/j.cretres.2004.04.004

Vickaryous MK. 2006. New information on the cranial anatomy of Edmontonia rugosidens

Gilmore, a Late Cretaceous nodosaurid dinosaur from Dinosaur Provincial Park,

Alberta. J Vert Paleontol. 26(4):1011-1013.

Vickaryous MK, Maryanska T, Weishampel DB. 2004. Ankylosauria. Pp. 363-392 In:

Weishampel DB, Dodson P,Osmólska H, editors. The Dinosauria. 2nd edition.

Berkeley: University of California Press.

Vickaryous MK, Russell AP, Currie PJ, Zhao X-J. 2001. A new ankylosaurid (Dinosauria:

Ankylosauria) from the Lower Cretaceous of China, with comments on ankylosaurian relationships. In: Currie, P. J. (ed.). Results from the Sino-Canadian Dinosaur Project. Part 3. Can J Earth Sci. 38:1767-1780.

Weishampel DB. 1984. The evolution of jaw mechanisms in ornithopod dinosaurs. Adv Anat Embryol Cell Biol. 87:1-110. 
Weishampel DB, Jianu CM. 2000. Plant-eaters and ghost lineages: dinosaurian herbivory revisited. In: Sues HD editor. Evolution of herbivory in terrestrial vertebrates: perspectives from the fossil record. p. 123-143.

Weishampel DB, Norman DB. 1989. Vertebrate herbivory in the Mesozoic: Jaws, plants, and evolutionary metrics. In: Farlow JO, editor. Paleobiology of the Dinosaurs. Geol Soc Am Spec Pap. 238:87-100.

Witmer LM. 1995. The extant phylogenetic bracket and the importance of reconstructing soft tissues in fossils. In: Thomason JJ, editor. Functional morphology in vertebrate paleontology. New York: Cambridge University Press. p 19-33.

Wood JM, Thomas RG, Visser J. 1988. Fluvial processes and vertebrate taphonomy: the upper Cretaceous Judith River Formation, south-central Dinosaur Provincial Park, Alberta, Canada. Palaeogeogr Palaeoclim Palaeoecol. 66:127-143.

Xu X, Wang X-L, You H-L. 2001. A juvenile ankylosaur from China. Naturwissenschaften $88: 297-300$.

Xu L, Lü J, Zhang X, Jia S, Hu W, Zhang J, Wu Y, Ji Q. 2007. A new nodosaurid dinosaur fossil from the Cretaceous Period of Ruyang, Henan. A Geol Sinica. 81:433-438.

Yang J-T, You H-L, Li D-Q, Kong D-L. 2013. First discovery of polacanthine ankylosaur dinosaur in Asia. Vertebr PalAsiatica. 51(4):265-277.

\section{Figure captions:}

Figure 1. Geographic and chronostratigraphic distribution of the most important ankylosaur taxa with known cranial material. For references of the different taxa see Table 1.

\begin{tabular}{|l|l|l}
\hline \\
0
\end{tabular}


Figure 2. Linear measurements used for morphometric analysis in this study (see also Supplementary data 1). A, Schematic drawing of an ankylosaur skull (Pawpawsaurus) in left lateral view; B, ventral view; C, ankylosaur mandible in left lateral view.

Figure 3. Interpretative drawing and SEM micrograph demonstrating the macro- and microwear features documented on the ankylosaur teeth.

Figure 4. Graphical output of PCA performed on the craniomandibular morphometric data. A, PC1-PC2 biplot. Two dimensional beam models placed in the four quadrants of the biplot represent ventral aspects of the skulls illustrating the most important cranial shape changes in this morphospace. Note that distribution of specimens reflects differences in skull shape rather than phylogenetic relationships. B, PC1-PC2 biplot. Note that ankylosaurid and nodosaurid taxa largely occupy different ranges in this biplot. Explanation of colour coding and legends are shown in the figure. Loadings of different variables (abbreviations in blue) on the PC axes are indicated by green lines. For variable abbreviations, see Figure 2 and text.

Figure 5. Muzzle shape variation in ankylosaurs. A-G, nodosaurids. H-L, ankylosaurids.

Figure 6. Muzzle width (blue shaded area) relative to quadrate condyle distance (blue dots) of different taxa mapped onto the phylogenetic tree of ankylosaurs (after Arbour and Currie (2016), modified to show only taxa with well preserved muzzles). Note the progressive

Törölt: 2015 widening of muzzle in both nodosaurids and ankylosaurids.

Figure 7. Craniodental features related to the mode of feeding in ankylosaurs. A, mandibular symphyseal region of an ankylosaurid dinosaur (TMP 1980.16.1685) in anterior view. B
Törölt: Euoplocephalus tutus 
mandibular symphyseal region of Hungarosaurus tormai (MTM 2007.25.2) in anterior view. C, tooth of the nodosaurid Sauropelta edwardsi (YPM VP 5350, image by Juri Miyamae). D, tooth of the ankylosaurid Pinacosaurus grangeri (ZPAL MG D-II/1). E, skull of Panoplosaurus mirus (CMN 2759) with the left lateral cheek plates in anterolateral view. F, skull of Edmontonia (AMNH 5381) with the left lateral cheek plates in lateral view. Anatomical abbreviations: ci, cingulum; cp, cheek plate; ed, edentulous margin; $\mathbf{f}$, foramen; fl, fluting; gr, groove; is, irregular surface; ssu, smooth surface; sy, mandibular symphysis.

Figure 8. Wear patterns on in situ ankylosaurian teeth. A-B, Gargoyleosaurus parkpinorum (DMNH 27726) left posterior maxillary teeth in lingual view. C-D, Silvisaurus condrayi (UKMNH 10296, image by Joshua Schmerge) left posterior dentary teeth in labial view. E-F, Hungarosaurus tormai (MTM 2007.25.2) right dentary teeth in labial view. G-H, Edmontonia (TMP. 98.98.01) posterior upper and lower teeth in labial view. I-J, Edmontonia (ROM 1215) left posterior maxillary teeth in lingual view. K-L, Euoplocephalus tutus (AMNH 5405) right maxillary tooth row in lingual view. M-N, 'Maleevus disparoserratus' (PIN 554) right maxillary teeth in lingual view. The other functional teeth are broken and not worn by occlusion. O-P, Saichania chulsanensis (PIN 3142/250) right upper and lower teeth in lingual view. Q-R, Pinacosaurus grangeri (ZPAL MG D-II/1) left maxillary teeth in lingual view. Anatomical abbreviations: awf, apical wear facet; bwf, bowl-like wear facet; cwf, wear facet on the carina; ewf, extended wear facet; swf, steeply inclined wear facet.

Figure 9. Macrowear features on the teeth of nodosaurid ankylosaurs. A, Gargoyleosaurus parkpinorum (DMNH 27726) maxillary tooth in labial view. B, Gargoyleosaurus parkpinorum (DMNH 27726) dentary tooth in lingual view. C, Europelta carbonensis associated tooth (FCPTD/MAP AR-1-325). D, Europelta carbonensis associated tooth

Törölt: $43 / 10$

Törölt: , image from Kirkland et al. 2013 
(FCPTD/MAP AR-1-324). E, Sauropelta edwardsi associated maxillary tooth (YPM VP

5351, image by Juri Miyamae). F, Sauropelta edwardsi associated maxillary tooth (YPM VP 5528, image by Juri Miyamae). G, Sauropelta edwardsi associated dentary tooth (YPM VP 5527, image by Juri Miyamae). H, Sauropelta edwardsi associated maxillary tooth (YPM VP 5350, image by Juri Miyamae). I, Struthiosaurus languedocensis associated tooth (UM2 OLD-19 CV) J-K, Hungarosaurus tormai right dentary tooth (MTM 2007.25.2) in labial view. $\underline{\mathrm{L}}_{\mathrm{Q}}$ Edmontonia (TMP 98.98.01) right dentary tooth in mesiolabial view. $\mathrm{M}$ Edmontonia (ROM 1215) left posterior maxillary tooth in lingual view. N. Edmontonia (ROM 1215) left posterior maxillary tooth in distolingual view. Anatomical abbreviations: a, apical; awf, apical wear facet; b, basal; cwf, wear facet on the carina; d, distal; de, dentine; eb, enamel bumps; edi, enamel-dentine interface; en, enamel; ewf, extended wear facet; m, mesial; sc, scratch; swf, steeply inclined wear facet; wci, worn cingulum; wci, worn cusp; we, worn enamel.

Figure 10. Macrowear features on the teeth of nodosaurid ankylosaurs. A, Edmontonia (CMN 8531 ) posterior right maxillary tooth. B, Edmontonia (ROM 1215) right $14^{\text {th }}$ maxillary tooth in lingual view. C, Edmontonia (ROM 1215) left posterior maxillary tooth in lingual view. D, Edmontonia (TMP 98.98.01) posterior right maxillary tooth. E, Edmontonia (ROM 1215) dentary tooth in labial view. F, Edmontonia (TMP 98.98.01) left $16^{\text {th }}$ dentary tooth. G, Panoplosaurus mirus (CMN 2759) associated tooth. H, Edmontonia (TMP 98.98.01) $5^{\text {th }}$ right maxillary tooth. Anatomical abbreviations: a, apical; b, basal; d, distal; de, dentine; eb, enamel bumps; edi, enamel-dentine interface; en, enamel; gr, groove, la, labial; li, lingual; m, mesial; or, ornamentation; p, pit, sc, scratch; swf, steeply inclined wear facet; wci, worn cingulum; wcu, worn cusps; we, worn enamel.
Törölt: /10

Törölt: , image from Kirkland et al. 2013 
Figure 11. Macrowear features on the teeth of ankylosaurids. A, Pinacosaurus grangeri (ZPAL MG D-II/1) right dentary tooth in lingual view. B, 'Maleevus disparoserratus' (PIN 554) right anterior maxillary tooth in lingual view. C, Saichania chulsanensis (PIN 3142/250) left maxillary tooth in apicolingual view. D, Saichania chulsanensis (PIN 3142/250) left posterior maxillary tooth in apicolingual view. E-F, Ankylosaurus magniventris (CMN 8880) associated tooth. G, Euoplocephalus tutus (AMNH 5405) left anterior maxillary teeth in mesiolingual view. H, Euoplocephalus tutus (AMNH 5405) right posterior maxillary tooth in lingual view. Anatomical abbreviations: a, apical; awf, apical wear facet; b, basal; d, distal; de, dentine; edi, enamel-dentine interface; en, enamel; la, labial; li, lingual; m, mesial; p, pit, sc, scratch; swf, steeply inclined wear facet; wci, worn cingulum; wcu, worn cusps.

Figure 12. Microwear features on the teeth of nodosaurids. A, Hungarosaurus tormai right dentary tooth (MTM 2007.25.2). B, Hungarosaurus tormai right dentary tooth (MTM 2007.25.2) worn cingulum region with obliqe scratches. C, Panoplosaurus mirus (CMN 2759) associated tooth. D, Edmontonia (CMN 8531) posterior right maxillary tooth. E, Edmontonia (TMP 98.98.01) $5^{\text {th }}$ right maxillary tooth. F, Edmontonia (TMP 98.98.01) $16^{\text {th }}$ left dentary tooth. G, Edmontonia (ROM 1215) left posterior maxillary tooth. H, Edmontonia (ROM 1215) associated dentary tooth. Anatomical abbreviations: a, apical; b, basal; d, distal; edi, enamel-dentine interface; la, labial; li, lingual; m, mesial; p, pit, sc, scratch.

Figure 13. Microwear features on ankylosaur teeth. A, Pinacosaurus grangeri (ZPal Mg-II/1) right dentay tooth. B, 'Maleevus disparoserratus' (PIN 554) right anterior maxillary tooth. C, Saichania chulsanensis (PIN 3142/250) left posterior maxillary tooth. D, Ankylosaurus magniventris (CMN 8880) associated tooth. E, Euoplocephalus tutus (AMNH 5405) right anterior maxillary tooth. F, Euoplocephalus tutus (AMNH 5405) right posterior maxillary 
tooth. G-H, Gargoyleosaurus parkpinorum (DMNH 27726) left maxillary tooth basal region. Anatomical abbreviations: a, apical; b, basal; d, distal; eb, enamel bumps; edi, enameldentine interface; en, enamel; la, labial; li, lingual; m, mesial; p, pit, sc, scratch; we, worn enamel.

Figure 14. Reconstruction of origin and insertion surfaces of the most important jaw adductor muscles in nodosaurids and ankylosaurids. A, nodosaurid (Edmontonia ROM 1215) and B, ankylosaurid (Saichania PIN 3142/250) skulls in ventral view with the origin surfaces. C, nodosaurid (Edmontonia ROM 1215) and D, ankylosaurid (Saichania PIN 3142/250) left mandibles in medial view with $\mathrm{E}$ and $\mathrm{F}$, their respective interpretative drawings indicating muscle insertion surfaces. G, orientation of the jaw adductor muscles in nodosaurid skull and mandible in lateral, and $\mathrm{H}$, in occipital view. Colours indicate different muscles. For muscle name abbreviations, see text.

Figure 15. The process of tooth occlusion and different types of jaw mechanism in ankylosaurs. A, jaw closure is orthal, tooth occlusion is usually absent, only local, or incidental. Wear (in red), if present, is minimal and occurs only apically. B, Orthal jaw closure with tooth occlusion. Attritional wear occurs along the whole tooth row, wear facets are steeper on the lower than on the upper teeth. C-D, Interaction of the upper and lower teeth in distal (C) and labial (D) views, when the mandible moves dorsally and posteriorly (at least 3-5 mm) (modified from Ösi et al. 2014a). Dashed lines in A-D show the way of the lower tooth crown during palinal power stroke. Wear facets on the lower teeth are steep, occasionally bowl-like, are shown in grey and light grey on the upper teeth. Red crosses connected with red solid lines represent the path of one of the lower teeth during the palinal power stroke. E, the anteroposterior movement of the mandible relative to the quadrate 
condyles (red). F, chewing cycle during simple orthal movement. G, chewing cycle during palinal movement. It starts with the opening of the mandibles (2). In the beginning of the closing phase, the mandible shifts forward (3). When the mandible is closed, and the upper and lower teeth come into contact (4), the mandible is pulled upward and backward bringing the lingual surface of the upper teeth and the labial surface of the lower teeth into a shearing contact (1). Green filled circles show the position and route of the anterior end of the lower jaw during chewing cycle.

Figure 16. Geographic and phylogenetic distribution and inferred evolution of key feeding specializations among thyreophorans. Simplified phylogenetic tree follows Arbour and Currie (2016), Arbour et al. (2016), and Thompson et al. (2012). Only those taxa are indicated that have available cranial material and dental wear pattern. Note that all the forms having biphasal jaw mechanism with tooth occlusion are from North America and Europe.

Table 1. List of ankylosaur species examined in this study.

Table 2. Macro- and microwear features of different ankylosaurs having in situ or associated dentition.

Table 3. Measurments of wear features in ankylosaurs. Length-width data are in $\mu \mathrm{m}$. 